\title{
A Comparison of Bullwhip Effect under Various Forecasting Techniques in Supply Chains with Two Retailers
}

\author{
Junhai Ma and Xiaogang Ma \\ College of Management and Economics, Tianjin University, Tianjin 300072, China \\ Correspondence should be addressed to Junhai Ma; lzqsly@126.com and Xiaogang Ma; xgm131006@126.com
}

Received 7 October 2013; Accepted 23 October 2013

Academic Editor: Massimiliano Ferrara

Copyright (C) 2013 J. Ma and X. Ma. This is an open access article distributed under the Creative Commons Attribution License, which permits unrestricted use, distribution, and reproduction in any medium, provided the original work is properly cited.

\begin{abstract}
We examine the impact of three forecasting methods on the bullwhip effect in a two-stage supply chain with one supplier and two retailers. A first order mixed autoregressive-moving average model $(\operatorname{ARMA}(1,1))$ performs the demand forecast and an order-up-to inventory policy characterizes the inventory decision. The bullwhip effect is measured, respectively, under the minimum meansquared error (MMSE), moving average (MA), and exponential smoothing (ES) forecasting techniques. The effect of parameters on the bullwhip effect under three forecasting methods is analyzed and the bullwhip effect under three forecasting methods is compared. Conclusions indicate that different forecasting methods lead to different bullwhip effects caused by lead time, underlying parameters of the demand process, market competition, and the consistency of demand volatility between two retailers. Moreover, some suggestions are present to help managers to select the forecasting method that yields the lowest bullwhip effect.
\end{abstract}

\section{Introduction}

In a supply chain, as moving backward from a downstream member to an upstream member, the variance of order quantities of orders placed by the downstream member to its (immediate) upstream member tends to be amplified. The discovery of the phenomenon can be dated back to Forrester $[1,2]$ who discussed its causes and possible remediation in the context of industrial dynamics. After that, more and more researchers recognized the existence of this phenomenon in supply chains. At MIT, the well known "beer game" which was widely used in teaching inventory management was developed by Sterman [3]. The above phenomenon was first called as "bullwhip effect" by Lee et al. [4, 5]. In works of Lee et al. $[4,5]$, demand signal processing, nonzero lead-time, order batching, supply shortages, and price fluctuation were recognized as five important sources which might lead to the emergence of the bullwhip effect in supply chains. In order to avoid the bullwhip effect, many managerial approaches have been done, that is, lead-time reduction, information sharing, or applying different replenishment rules for the inventory system.

Among the most important issues that need to be addressed in dealing with the bullwhip effect, quantifying the bullwhip effect is a challenge. In the following papers, the supply chain might employ different demand processes and different forecasting methods. Using a first-order autoregressive $(\mathrm{AR}(1))$ demand process, Chen et al. [6,7] investigated the impact of the MA and ES forecasting methods on the bullwhip effect for a simple, two-stage supply chain with one supplier and one retailer. Likewise, Xu et al. [8] conducted a similar research for the lead-time demand that is forecasted with the ES method. Luong [9] measured the bullwhip effect for a simple two-stage supply chain that includes only one retailer and one supplier in the environment where the retailer employs the order-up-to inventory policy for their inventory and demand forecast is performed through the AR(1) model, and the effect of autoregressive coefficient and lead time on this measure was investigated. For the same two-stage supply chain, Duc et al. [10] investigated effects of the autoregressive coefficient, the moving average parameter, and the lead time on the bullwhip effect when the retailer performed through the ARMA $(1,1)$ model. Duc et al. [11] examined the impact of a third-party warehouse on the bullwhip effect in a three-stage supply chain with one supplier, one third-party warehouse and two retailers. Then, they found that the existence of the third-party warehouse has no influence on the bullwhip effect when the lead times 
of the third-party warehouse, and the two retailers are equal. Zhang [12] measured the bullwhip effect for the simple supply chain with $\mathrm{AR}(1)$ demand process under various forecasting methods, and considered the impact of forecasting methods on the bullwhip effect. Feng and Ma [13] compared the MMSE, MA, and ES forecasting methods for the simple supply chain with $\operatorname{ARMA}(1,1)$ demand process by using the dynamic simulation.

Ferrara et al. [14] examined how performances and characteristics of innovation poles and science park affect various aspects of Italian regional economies at NUTS 2 level. In particular, they found that impacts are different by geographic location but the effects are still evident even in the aggregate model. The number of IP/SP per region seems to display a positive role in sustaining the economic growth of corresponding regions. In addition, the patenting activity and the creation of research centers foster the growth of affiliated firms, which in turn affects regional economy's parameters. To the contrary, the distance between the IP/SP and affiliated firms reduces the growing potential of the latter. Moreover, firms within an IP/SP turn out to outperforms (largely) the regional average. Finally, they found that more recent structures tend to be more prone to both patenting activity and high-level growth.

The supply chain model usually has only one retailer in the previous researches which study on the bullwhip effect, but the new supply chain we will build has two retailers. This supply chain is more in line with the structure of market. Pindyck and Rubinfeld [15] thought that the ARMA model often fits the time series of the demand process better than the AR model because the demand process usually has characteristics of both moving average and autoregressive process. The two retailers both employ the $\operatorname{ARMA}(1,1)$ demand process, and both use the MMSE, MA, and ES method to forecast the lead-time demand, respectively. Our research not only determines an exact measure of the bullwhip effect but also analyzes the impact of parameters on the bullwhip effect under various forecasting methods and compare the impact of three forecasting method on the bullwhip effect.

The rest of this paper is organized as follow. Section 2 presents a new supply chain model containing two retailers which both follow the $\operatorname{ARMA}(1,1)$ demand process and employ the order-up-to stock policy. In Section 3, the bullwhip effect measure for MMSE, MA, and ES forecasting method is derived. In Section 4, we analyze the effects of parameters on the bullwhip effect under different forecasting methods and compare the impact of three forecasting methods on the bullwhip effect. At last, some concluding remarks are discussed in Section 5.

\section{Supply Chain Model}

2.1. Demand Process. In this research, a two-stage supply chain with one supplier and two retailers is developed. Two retailers face customer demands and place orders to the supplier, respectively. We consider that retailer 1 faces an $\operatorname{ARMA}(1,1)$ demand model as follows:

$$
D_{1, t}=\delta_{1}+\phi_{1} D_{1, t-1}+\varepsilon_{1, t}-\theta_{1} \varepsilon_{1, t-1} .
$$

Here, $\phi_{1}$ and $\theta_{1}$ are the autoregressive and moving average coefficients of this demand model, where $-1<\phi_{1}<1,-1<$ $\theta_{1}<1 . \varepsilon_{1, t}$ is independent and identically distributed from a symmetric distribution with mean 0 and variance $\sigma^{2}$. And, we have

$$
\begin{gathered}
E\left(D_{1}\right)=\frac{\delta_{1}}{1-\phi_{1}}, \\
\operatorname{Var}\left(D_{1}\right)=\frac{1+\theta_{1}^{2}-2 \phi_{1} \theta_{1}}{1-\phi_{1}^{2}} \sigma_{1}^{2} .
\end{gathered}
$$

Similarly, retailer 2 also faces an $\operatorname{ARMA}(1,1)$ demand model as follows:

$$
D_{2, t}=\delta_{2}+\phi_{2} D_{2, t-1}+\varepsilon_{2, t}-\theta_{2} \varepsilon_{2, t-1},
$$

here, $\phi_{2}$ and $\theta_{2}$ have same properties with $\phi_{1}$ and $\theta_{1}$ accordingly. So, we also have

$$
\begin{gathered}
E\left(D_{2}\right)=\frac{\delta_{2}}{1-\phi_{2}}, \\
\operatorname{Var}\left(D_{2}\right)=\frac{1+\theta_{2}^{2}-2 \phi_{2} \theta_{2}}{1-\phi_{2}^{2}} \sigma_{2}^{2} .
\end{gathered}
$$

2.2. Inventory Policy. Assumption of the order-up-to inventory policy is used in this supply chain system for its inventory management. Two retailers both employ the order-up-to inventory policy. Retailer 1 places an order of quantity $q_{1, t}$ to the supplier at the beginning of period $t$. And the order quantity $q_{1, t}$ can be given as

$$
q_{1, t}=S_{1, t}-S_{1, t-1}+D_{1, t-1},
$$

where $S_{1, t}$ is the order-up-to lever of retailer 1 at period $t$, and it can be determined by the lead-time demand as

$$
S_{1, t}=\widehat{D}_{1, t}^{L_{1}}+z \widehat{\sigma}_{1, t}^{L_{1}},
$$

where $\widehat{D}_{1, t}^{L_{1}}$ is the forecast for the lead-time demand of retailer 1 which is depend on the forecasting method and $L_{1}, \widehat{\sigma}_{1, t}^{L_{1}}$ is the standard deviation of lead-time demand forecast error, and $z$ is the normal $z$-score that can be determined based on a given service level. Duc et al. [10] has proofed that $\widehat{\sigma}_{1, t}^{L_{1}}$ does not depend on $t$ and has no influence on the bullwhip effect.

For retailer 2, the order quantity $q_{2, t}$ also can be given as

$$
q_{2, t}=S_{2, t}-S_{2, t-1}+D_{2, t-1} .
$$

The order-up-to level of retailer 2 at period $t$ is

$$
S_{2, t}=\widehat{D}_{2, t}^{L_{2}}+z \widehat{\sigma}_{2, t}^{L_{2}} .
$$

Equations (7)-(8) have the same meaning with (5)-(6).

2.3. Forecasting Technique. In this paper, we assume that two retailers both use the same forecasting technique to forecast the lead-time demand. In Section 3, the bullwhip effect will be measured, respectively, under the MMES, MA, and ES forecasting methods. Those three forecasting methods will be introduced in this section firstly. 
2.3.1. The MMSE Forecasting Method. In the MMSE forecasting method, the forecast for the lead-time demand can be given as

$$
\widehat{D}_{t}^{L}=\widehat{D}_{t}+\widehat{D}_{t+1}+\cdots+\widehat{D}_{t+L-1}=\sum_{i=0}^{L-1} \widehat{D}_{t+i},
$$

where $\widehat{D}_{t}$ is the forecast for the demand at period $t$, and can be determined as

$$
\widehat{D}_{t+i}=E\left[D_{t+i} \mid D_{t-1}, D_{t-2}, \ldots\right] .
$$

2.3.2. The MA Forecasting Method. Using the MA forecasting method, the forecast for the lead-time demand can be given as

$$
\widehat{D}_{t}^{L}=\frac{L}{k} \sum_{i=1}^{k} D_{t-i}
$$

where $k$ is the span (number of date points) for the MA forecasting method.

2.3.3. The ES Forecasting Method. The ES forecasting method is an adaptive algorithm in which one-period-ahead forecast is adjusted with a fraction of the forecasting error, and can be written as

$$
\widehat{D}_{t}^{L}=\alpha D_{t-1}+(1-\alpha) \widehat{D}_{t-1}^{L},
$$

where $\alpha(0<\alpha<1)$ denotes the fraction used in the method, also called the smoothing exponent.

\section{The Measure of the Bullwhip Effect under Various Forecasting Techniques}

In this section, the measure of the bullwhip effect under the MMSE, MA, and ES forecasting methods will be derived, respectively.

Total demand which two retailers face is

$$
D_{t}=D_{1, t}+D_{2, t} .
$$

The variance of $D_{t}$ is determined as

$$
\begin{aligned}
\operatorname{Var}\left(D_{t}\right) & =\operatorname{Var}\left(D_{1, t}+D_{2, t}\right) \\
& =\operatorname{Var}\left(D_{1, t}\right)+\operatorname{Var}\left(D_{2, t}\right)+2 \operatorname{Cov}\left(D_{1, t}, D_{2, t}\right) .
\end{aligned}
$$

Two retailers face the same perfectly competitive market, and their demands present a negative correlation. We assume that the correlation coefficient is $\psi(-1 \leq \psi \leq 0)$, we can get

$$
\operatorname{Cov}\left(D_{1, t}, D_{2, t}\right)=\psi \sqrt{\operatorname{Var}\left(D_{1, t}\right)} \sqrt{\operatorname{Var}\left(D_{2, t}\right)} .
$$

Using (15) in (14), we can get

$$
\begin{aligned}
\operatorname{Var}\left(D_{t}\right)= & \operatorname{Var}\left(D_{1, t}+D_{2, t}\right) \\
= & \operatorname{Var}\left(D_{1, t}\right)+\operatorname{Var}\left(D_{2, t}\right) \\
& +2 \psi \sqrt{\operatorname{Var}\left(D_{1, t}\right)} \sqrt{\operatorname{Var}\left(D_{2, t}\right)} .
\end{aligned}
$$

3.1. The Measure of the Bullwhip Effect under the MMSE Forecasting Method. According to Duc et al. [10], for the MMSE forecasting method, the order quantity of retailer 1 can be determined as

$$
\begin{aligned}
q_{1, t}= & \frac{\phi_{1}\left(1-\phi_{1}^{L_{1}}\right)}{1-\phi_{1}} D_{1, t-1}-\frac{\theta_{1}\left(1-\phi_{1}^{L_{1}}\right)}{1-\phi_{1}} \varepsilon_{t-1} \\
& -\left(\frac{\phi_{1}\left(1-\phi_{1}^{L_{1}}\right)}{1-\phi_{1}} D_{1, t-2}-\frac{\theta_{1}\left(1-\phi_{1}^{L_{1}}\right)}{1-\phi_{1}} \varepsilon_{t-2}\right)+D_{1, t-1} \\
= & \left(\phi_{1} A_{1}+1\right) D_{1, t-1}-\phi_{1} A_{1} D_{1, t-2} \\
& -\theta_{1} A_{1} \varepsilon_{1, t-1}+\theta_{1} A_{1} \varepsilon_{1, t-2},
\end{aligned}
$$

where $A_{1}=\left(1-\phi_{1}^{L_{1}}\right) /\left(1-\phi_{1}\right)$.

In the same, we also have

$$
\begin{aligned}
q_{2, t}= & \left(\phi_{2} A_{2}+1\right) D_{2, t-1}-\phi_{2} A_{2} D_{2, t-2} \\
& -\theta_{2} A_{2} \varepsilon_{2, t-1}+\theta_{2} A_{2} \varepsilon_{2, t-2},
\end{aligned}
$$

where $A_{2}=\left(1-\phi_{2}^{L_{2}}\right) /\left(1-\phi_{2}\right)$.

Total order quantity of period $t$ is

$$
\begin{aligned}
q_{t}= & \left(\phi_{1} A_{1}+1\right) D_{1, t-1}-\phi_{1} A_{1} D_{1, t-2}-\theta_{1} A_{1} \varepsilon_{1, t-1} \\
& +\theta_{1} A_{1} \varepsilon_{1, t-2}+\left(\phi_{2} A_{2}+1\right) D_{2, t-1}-\phi_{2} A_{2} D_{2, t-2} \\
& -\theta_{2} A_{2} \varepsilon_{2, t-1}+\theta_{2} A_{2} \varepsilon_{2, t-2} .
\end{aligned}
$$

Proposition 1. The variance of the total order quantity of period $t$ under the MMSE forecasting method can be given as

$$
\begin{aligned}
& \operatorname{Var}\left(q_{t}\right) \\
& =\left(\left(\phi_{1} A_{1}+1\right)^{2}+\left(\phi_{1} A_{1}\right)^{2}\right. \\
& +\frac{2\left(\theta_{1} A_{1}\right)^{2}\left(1-\phi_{1}^{2}\right)}{1+\theta_{1}^{2}-2 \phi_{1} \theta_{1}} \\
& -\frac{2 \phi_{1} A_{1}\left(\phi_{1} A_{1}+1\right)\left(\phi_{1}-\theta_{1}\right)\left(1-\phi_{1} \theta_{1}\right)}{1+\theta_{1}^{2}-2 \phi_{1} \theta_{1}} \\
& +\frac{2 \theta_{1} A_{1}\left(\phi_{1} A_{1}+1\right)\left(\phi_{1}-\theta_{1}-1\right)\left(1-\phi_{1}{ }^{2}\right)}{1+\theta_{1}{ }^{2}-2 \phi_{1} \theta_{1}} \\
& \left.-\frac{2 \phi_{1} \theta_{1} A_{1}^{2}\left(1-\phi_{1}{ }^{2}\right)}{1+\theta_{1}^{2}-2 \phi_{1} \theta_{1}}\right) \operatorname{Var}\left(D_{1}\right) \\
& +\left(\left(\phi_{2} A_{2}+1\right)^{2}+\left(\phi_{2} A_{2}\right)^{2}\right. \\
& +\frac{2\left(\theta_{2} A_{2}\right)^{2}\left(1-\phi_{2}^{2}\right)}{1+\theta_{2}^{2}-2 \phi_{2} \theta_{2}} \\
& -\frac{2 \phi_{2} A_{2}\left(\phi_{2} A_{2}+1\right)\left(\phi_{2}-\theta_{2}\right)\left(1-\phi_{2} \theta_{2}\right)}{1+\theta_{2}^{2}-2 \phi_{2} \theta_{2}}
\end{aligned}
$$




$$
\begin{aligned}
& +\frac{2 \theta_{2} A_{2}\left(\phi_{2} A_{2}+1\right)\left(\phi_{2}-\theta_{2}-1\right)\left(1-\phi_{2}^{2}\right)}{1+\theta_{2}^{2}-2 \phi_{2} \theta_{2}} \\
& \left.-\frac{2 \phi_{2} \theta_{2} A_{2}^{2}\left(1-\phi_{2}^{2}\right)}{1+\theta_{2}^{2}-2 \phi_{2} \theta_{2}}\right) \operatorname{Var}\left(D_{2}\right) \\
& +2\left(\left(\phi_{1} A_{1}+1\right)\left(\phi_{2} A_{2}+1\right)-\phi_{2} A_{2}\left(\phi_{1} A_{1}+1\right) \phi_{1}\right. \\
& \left.-\phi_{1} A_{1}\left(\phi_{2} A_{2}+1\right) \phi_{2}+\phi_{1} \phi_{2} A_{1} A_{2}\right) \\
& \times \psi \sqrt{\operatorname{Var}\left(D_{1, t}\right) \operatorname{Var}\left(D_{2, t}\right)} .
\end{aligned}
$$

Proof. See the Appendix

For simplicity, (20) can be written as

$$
\begin{aligned}
\operatorname{Var} & \left(q_{t}\right) \\
= & H_{1} \operatorname{Var}\left(D_{1, t}\right)+H_{2} \operatorname{Var}\left(D_{2, t}\right) \\
& +H_{3} \psi \sqrt{\operatorname{Var}\left(D_{1, t}\right) \operatorname{Var}\left(D_{2, t}\right)},
\end{aligned}
$$

where $H_{1}$ is the coefficient of $\operatorname{Var}\left(D_{1, t}\right), H_{2}$ is the coefficient of $\operatorname{Var}\left(D_{2, t}\right)$, and $H_{3}$ is the coefficient of $\psi \sqrt{\operatorname{Var}\left(D_{1, t}\right) \operatorname{Var}\left(D_{2, t}\right)}$ in (20).

From (16) and (21), the measure of the bullwhip effect under the MMSE forecasting method, denoted as BWE $\mathrm{BMSE}_{\mathrm{MMS}}$ here, can be determined as

$$
\mathrm{BWE}_{\mathrm{MMSE}}=\frac{H_{1}+H_{2} \gamma^{2}+H_{3} \psi \gamma}{1+\gamma^{2}+2 \psi \gamma},
$$

where $\gamma=\sqrt{\left(\operatorname{Var}\left(D_{2, t}\right)\right) /\left(\operatorname{Var}\left(D_{1, t}\right)\right)}$, which means the consistency of demand volatility between two retailers.

3.2. The Measure of the Bullwhip Effect under the MA Forecasting Method. According to (5)-(6) and (11), we can get the order of retailer 1

$$
\begin{aligned}
q_{1, t}= & S_{1, t}-S_{1, t-1}+D_{1, t-1} \\
= & \frac{L_{1}}{k}\left(\sum_{i=1}^{k} D_{t-i}-\sum_{i=1}^{k} D_{t-1-i}\right) \\
& +z\left(\hat{\sigma}_{1, t}^{L_{1}}-\widehat{\sigma}_{1, t-1}^{L_{1}}\right)+D_{1, t-1} \\
= & \left(1+\frac{L_{1}}{k}\right) D_{1, t-1}-\frac{L_{1}}{k} D_{1, t-k-1}+z\left(\widehat{\sigma}_{1, t}^{L_{1}}-\widehat{\sigma}_{1, t-1}^{L_{1}}\right) .
\end{aligned}
$$

We know that $\widehat{\sigma}_{1, t}^{L_{1}}$ does not depend on $t$, so (23) equals

$$
q_{1, t}=\left(1+\frac{L_{1}}{k}\right) D_{1, t-1}-\frac{L_{1}}{k} D_{1, t-k-1},
$$

where $k$ is the span of the MA forecasting method for retailer 1. Retailer 2 has the same span $k$, so the order quantity of retailer 2 is

$$
q_{2, t}=\left(1+\frac{L_{2}}{k}\right) D_{2, t-1}-\frac{L_{2}}{k} D_{2, t-k-1} .
$$

The total order quantity of retailers in period $t$ is

$$
\begin{aligned}
q_{t}= & q_{1, t}+q_{2, t}=\left(1+\frac{L_{1}}{k}\right) D_{1, t-1} \\
& -\frac{L_{1}}{k} D_{1, t-k-1}+\left(1+\frac{L_{2}}{k}\right) D_{2, t-1}-\frac{L_{2}}{k} D_{2, t-k-1} .
\end{aligned}
$$

Proposition 2. The variance of the total order quantity at period $t$ under the MA forecasting method can be given as

$$
\begin{aligned}
\operatorname{Var}\left(q_{t}\right)=( & \left(1+\frac{L_{1}}{k}\right)^{2}+\left(\frac{L_{1}}{k}\right)^{2}-2 \frac{L_{1}}{k}\left(1+\frac{L_{1}}{k}\right) \\
& \left.\times\left(\frac{\left(\phi_{1}-\theta_{1}\right)\left(1-\phi_{1} \theta_{1}\right)}{1+\theta_{1}^{2}-2 \phi_{1} \theta_{1}}\right) \phi_{1}^{k-1}\right) \operatorname{Var}\left(D_{1, t}\right) \\
& +\left(\left(1+\frac{L_{2}}{k}\right)^{2}+\left(\frac{L_{2}}{k}\right)^{2}-2 \frac{L_{2}}{k}\left(1+\frac{L_{2}}{k}\right)\right. \\
& \left.\times\left(\frac{\left(\phi_{2}-\theta_{2}\right)\left(1-\phi_{2} \theta_{2}\right)}{1+\theta_{2}^{2}-2 \phi_{2} \theta_{2}}\right) \phi_{2}^{k-1}\right) \\
\times & \operatorname{Var}\left(D_{2, t}\right)+\left(2\left(1+\frac{L_{1}}{k}\right)\left(1+\frac{L_{2}}{k}\right)\right. \\
& -2 \frac{L_{2}}{k}\left(1+\frac{L_{1}}{k}\right) \phi_{1}^{k} \\
& \times \psi \sqrt{\operatorname{Var}\left(D_{1, t}\right) \operatorname{Var}\left(D_{2, t}\right) .}
\end{aligned}
$$

Proof. See the Appendix.

For simplicity, (27) can be written as

$$
\begin{aligned}
\operatorname{Var}\left(q_{t}\right)= & J_{1} \operatorname{Var}\left(D_{1, t}\right)+J_{2} \operatorname{Var}\left(D_{2, t}\right) \\
& +J_{3} \psi \sqrt{\operatorname{Var}\left(D_{1, t}\right) \operatorname{Var}\left(D_{2, t}\right)},
\end{aligned}
$$

where $J_{1}$ is the coefficient of $\operatorname{Var}\left(D_{1}\right), J_{2}$ is the coefficient of $\operatorname{Var}\left(D_{2, t}\right)$, and $J_{3}$ is the coefficient of $\psi \sqrt{\operatorname{Var}\left(D_{1, t}\right) \operatorname{Var}\left(D_{2, t}\right)}$ in (27).

From (16) and (28), the measure of the bullwhip under the MA forecasting method, denoted as $\mathrm{BWE}_{\mathrm{MA}}$ here, can be determined as

$$
\mathrm{BWE}_{\mathrm{MA}}=\frac{J_{1}+J_{2} \gamma^{2}+J_{3} \psi \gamma}{1+\gamma^{2}+2 \psi \gamma},
$$

the same, where $\gamma=\sqrt{\left(\operatorname{Var}\left(D_{2, t}\right)\right) /\left(\operatorname{Var}\left(D_{1, t}\right)\right)}$.

3.3. The Measure of the Bullwhip Effect under the ES Forecasting Method. According to Zhang [12], we know that the order quantity of retailer 1 at period $t$ under the ES forecasting method is

$$
q_{1, t}=D_{1, t}+\alpha_{1} L_{1}\left(D_{1, t}-\widehat{D}_{1, t}\right)
$$


where $\alpha_{1}$ is the smoothing exponent of retailer 1 and $\widehat{D}_{1, t}$ is the forecast of the demand at period $t$ for retailer 1 .

The same, the order quantity of retailer 2 at period $t$ under the ES forecasting method is

$$
q_{2, t}=D_{2, t}+\alpha_{2} L_{2}\left(D_{2, t}-\widehat{D}_{2, t}\right),
$$

where $\alpha_{2}$ is the smoothing exponent of retailer 2 and $\widehat{D}_{2, t}$ is the forecast of the demand at period $t$ for retailer 2 .

Hence, total order quantity of two retailers at period $t$ is

$$
\begin{aligned}
q_{t}= & \left(1+\alpha_{1} L_{1}\right) D_{1, t}-\alpha_{1} L_{1} \widehat{D}_{1, t} \\
& +\left(1+\alpha_{2} L_{2}\right) D_{2, t}-\alpha_{2} L_{2} \widehat{D}_{2, t} .
\end{aligned}
$$

Proposition 3. The variance of the total order quantity at period $t$ under the ES forecasting method can be given as

$$
\begin{aligned}
& \operatorname{Var}\left(q_{t}\right) \\
& =\left(\left(1+\alpha_{1} L_{1}\right)^{2}+\frac{\left(\alpha_{1} L_{1}\right)^{2}\left(1+\left(1-\alpha_{1}\right) \phi_{1}\right)}{\alpha_{1}\left(2-\alpha_{1}\right)\left(1-\left(1-\alpha_{1}\right) \phi_{1}\right)}\right. \\
& \left.-\frac{2 \alpha_{1}^{2} L_{1}\left(1+\alpha_{1} L_{1}\right)\left(\phi_{1}-\theta_{1}\right)\left(1-\phi_{1} \theta_{1}\right)}{\left(1-\phi_{1}\left(1-\alpha_{1}\right)\right)\left(1+\theta_{1}^{2}-2 \phi_{1} \theta_{1}\right)}\right) \\
& \times \operatorname{Var}\left(D_{1, t}\right) \\
& +\left(\left(1+\alpha_{2} L_{2}\right)^{2}+\frac{\left(\alpha_{2} L_{2}\right)^{2}\left(1+\left(1-\alpha_{2}\right) \phi_{2}\right)}{\alpha_{2}\left(2-\alpha_{2}\right)\left(1-\left(1-\alpha_{2}\right) \phi_{2}\right)}\right. \\
& \left.-\frac{2 \alpha_{2}^{2} L_{2}\left(1+\alpha_{2} L_{2}\right)\left(\phi_{2}-\theta_{2}\right)\left(1-\phi_{2} \theta_{2}\right)}{\left(1-\phi_{2}\left(1-\alpha_{2}\right)\right)\left(1+\theta_{2}^{2}-2 \phi_{2} \theta_{2}\right)}\right) \\
& \times \operatorname{Var}\left(D_{2, t}\right) \\
& +\left(2\left(1+\alpha_{1} L_{1}\right)\left(1+\alpha_{2} L_{2}\right)+\frac{2 \alpha_{2}^{2} \phi_{1} L_{2}\left(1+\alpha_{1} L_{1}\right)}{1-\phi_{1}\left(1-\alpha_{2}\right)}\right. \\
& -\frac{2 \alpha_{1}^{2} L_{1}\left(1+\alpha_{2} L_{2}\right) \phi_{2}}{1-\phi_{2}\left(1-\alpha_{1}\right)} \\
& \left.+\frac{2 \alpha_{1} \alpha_{2} L_{1} L_{2} \phi_{2}\left(1-\alpha_{2}\right)}{\left(1-\left(1-\alpha_{1}\right)\left(1-\alpha_{2}\right)\right)\left(1-\phi_{2}\left(1-\alpha_{2}\right)\right)}\right) \\
& \times \psi \sqrt{\operatorname{Var}\left(D_{1, t}\right) \operatorname{Var}\left(D_{2, t}\right)} .
\end{aligned}
$$

Proof. See the Appendix.

For simplicity, (33) can be written as

$$
\begin{aligned}
\operatorname{Var}\left(q_{t}\right)= & R_{1} \operatorname{Var}\left(D_{1, t}\right)+R_{2} \operatorname{Var}\left(D_{2, t}\right) \\
& +R_{3} \psi \sqrt{\operatorname{Var}\left(D_{1, t}\right) \operatorname{Var}\left(D_{2, t}\right)},
\end{aligned}
$$

where $R_{1}$ is the coefficient of $\operatorname{Var}\left(D_{1}\right), R_{2}$ is the coefficient of $\operatorname{Var}\left(D_{2, t}\right)$, and $R_{3}$ is the coefficient of $\psi \sqrt{\operatorname{Var}\left(D_{1, t}\right) \operatorname{Var}\left(D_{2, t}\right)}$ in (33).

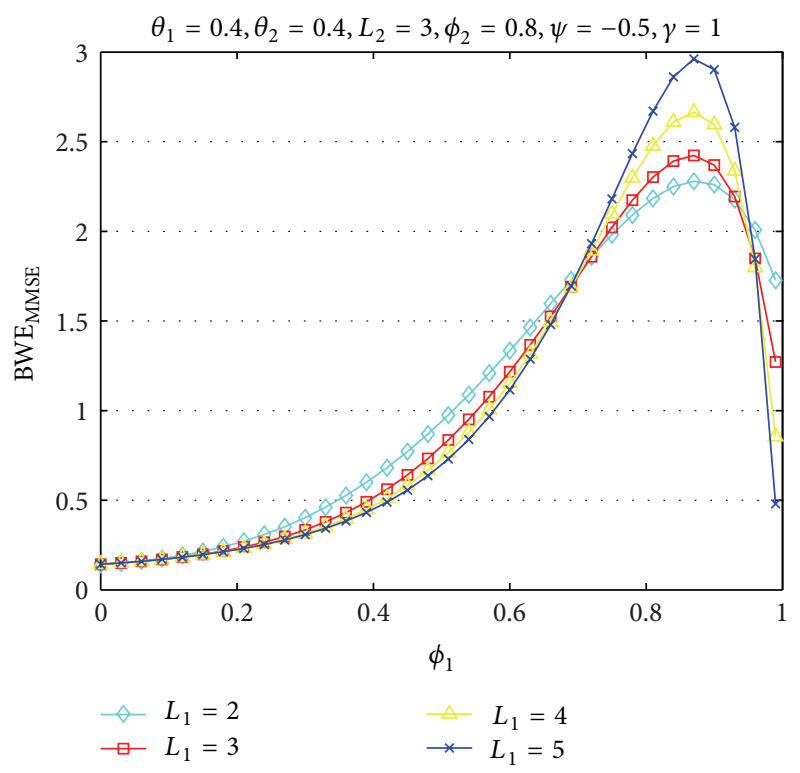

FIGURE 1: Impact of $\phi_{1}$ on bullwhip effect for different $L_{1}$ under the MMSE.

From (16) and (34), the measure of the bullwhip under the ES forecasting method, denoted as $\mathrm{BWE}_{\mathrm{ES}}$ here, can be determined as

$$
\mathrm{BWE}_{\mathrm{ES}}=\frac{R_{1}+R_{2} \gamma^{2}+R_{3} \psi \gamma}{1+\gamma^{2}+2 \psi \gamma},
$$

the same, where $\gamma=\sqrt{\left(\operatorname{Var}\left(D_{2, t}\right)\right) /\left(\operatorname{Var}\left(D_{1, t}\right)\right)}$.

\section{Analysis and Comparison for Various Forecasting Methods}

In this section, impacts of demand process, inventory policy, forecasting methods, and other parameters on the bullwhip effect will be analyzed and illustrated by using numerical experiments. Results of these numerical experiments highlight the economic and managerial application of our model and findings.

4.1. The Effect of Parameters on the Bullwhip Effect under the MMSE. Figures 1-3 simulate the expression of the bullwhip effect under the MMSE forecasting method to illustrate the impact of parameters on the bullwhip effect. Luong [9] has indicated that the bullwhip effect occurs only when the autoregressive coefficient is positive in the demand process under MMSE forecasting method. So, we vary the autoregressive coefficient of retailer $1 \phi_{1}$ from 0 to 1 and set $\theta_{2}=0.5$, $L_{2}=3, \phi_{1}=0.8, \phi_{2}=0.8, \psi=-0.5$, and $\gamma=1$ in Figure 1 to reveal the impact of $\phi_{1}$ on the bullwhip effect. We observe that the bullwhip effect increases slowly with the increase of $\phi_{1}$, and the bullwhip effect begins to decrease rapidly when it reaches the maximum value. The bullwhip effect does not occur only when $\phi_{1}$ increases to a certain value, and those values are different for the different $L_{1}$. For $L_{1}$, when $\phi_{1}$ is 


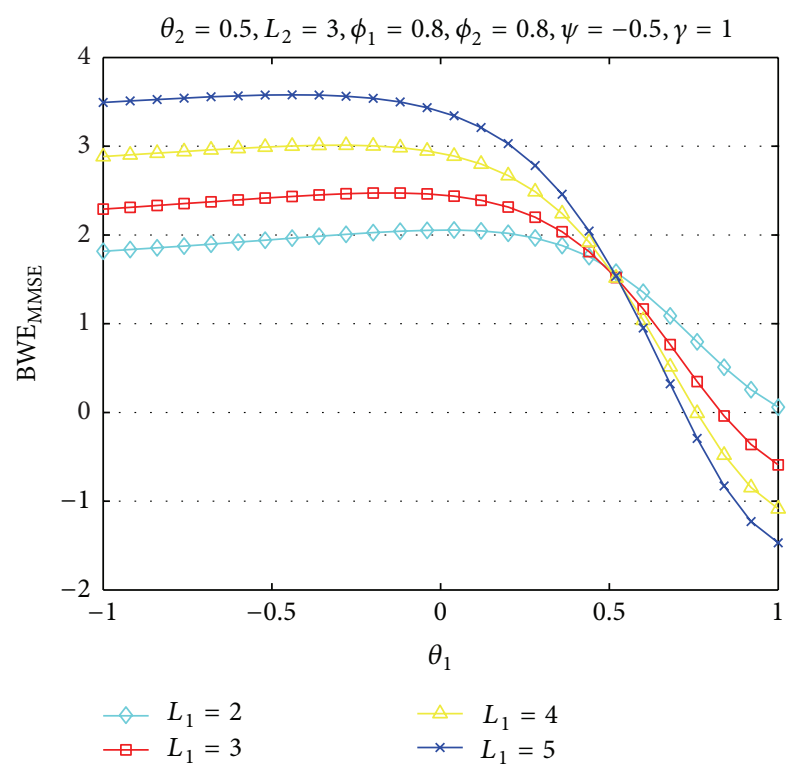

FIGURE 2: Impact of $\theta_{1}$ on bullwhip effect for different $L_{1}$ under the MMSE.

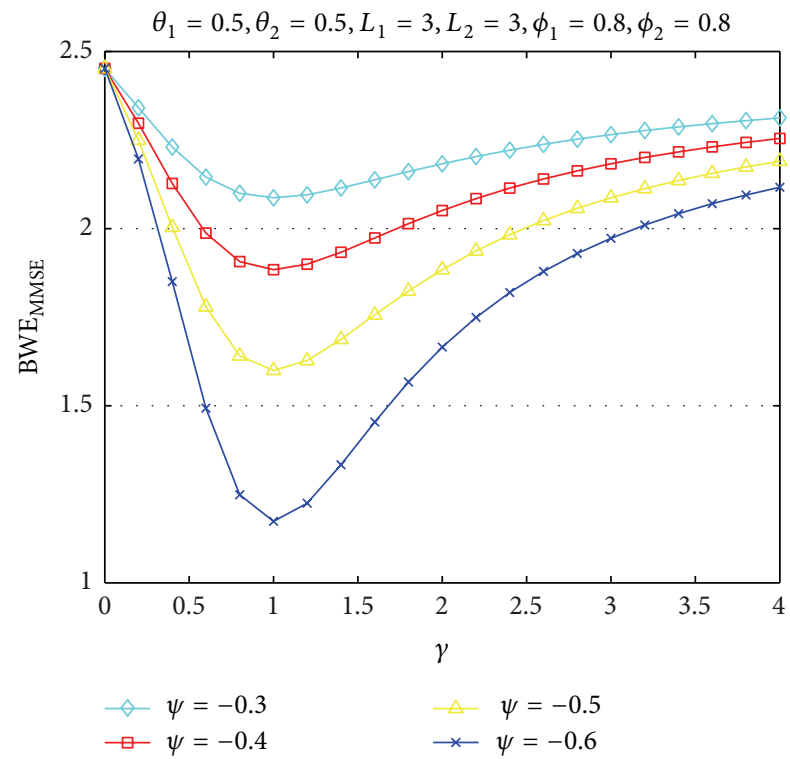

FIGURE 3: Impact of $\gamma$ on bullwhip effect for different $\psi$ under the MMSE.

smaller than a certain value, the smaller it is the larger the bullwhip effect is; when $\phi_{1}$ is larger than that certain value and smaller than another certain value, then the larger it is the larger the bullwhip effect is; and when $\phi_{1}$ is larger than another certain value, the smaller it is the larger the bullwhip effect is.

Figure 2 shows the impact of $\theta_{1}$ on the bullwhip effect when we set $\theta_{2}=0.5, L_{2}=3, \phi_{1}=0.8, \phi_{2}=0.8, \psi=-0.5$, and $\gamma=1$. The bullwhip effect increases slowly firstly, and then decreases slowly with the increase of $\theta_{1}$.

Figure 3 investigates how parameters $\gamma$ and $\psi$ affect the bullwhip effect when we set $\theta_{1}=0.5, \theta_{2}=0.5, L_{1}=3$,

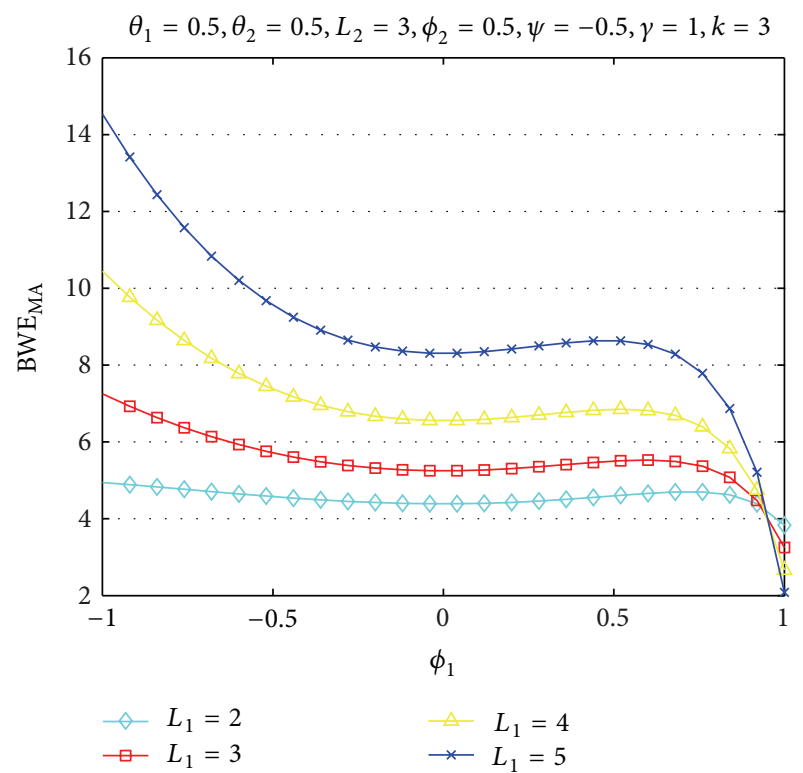

FIGURE 4: Impact of $\phi_{1}$ on bullwhip effect for different $L_{1}$ under the MA.

$L_{2}=3, \phi_{1}=0.8$, and $\phi_{2}=0.8$. The bullwhip effect decreases firstly, and it reaches the minimum value when $\gamma=1$, then increases with the increase of $\gamma$. The phenomenon illustrates that the bullwhip effect is smaller when the volatility of demand between two retailers is more consistent. Specially, the bullwhip effect attains a minimum when two retailers have the same volatility of demand. For the correlative coefficient of demand between two retailers, the larger it is the larger the bullwhip effect is. This phenomenon indicates that the intense competition between two retailers can reduce the bullwhip effect.

4.2. The Effect of Parameters on the Bullwhip Effect under the $M A$. Figures 4-7 simulate the expression of the bullwhip effect under the MA forecasting method to illustrate the impact of parameters on the bullwhip effect. We vary $\phi_{1}$ from -1 to 1 , shift $L_{1}$, and fix values for all other parameters in Figure 4. It shows that the bullwhip effect decreases slowly firstly when $-1 \leq \phi_{1} \leq 0$, then increases slowly and decreases rapidly when $0<\phi_{1} \leq 1$. We also observe that the greater the lead-time of retailer 1 is the greater the bullwhip effect when $\phi_{1}$ is less than a certain number, and the greater the lead-time of retailer 1 is the less the bullwhip effect when $\phi_{1}$ is greater than that certain number.

Figure 5 shows the impact of $\theta_{1}$ on the bullwhip effect when we set $\theta_{2}=0.5, L_{2}=3, \phi_{1}=0.5, \phi_{2}=0.5, \psi=-0.5$, $\gamma=1$. The bullwhip effect increases slowly all the time with the increase of $\theta_{1}$. And, in this situation, we shift the lead-time of retailer 1 , and then the bullwhip effect becomes greater with the increase of $L_{1}$.

We shift the span for the MA forecasting method to examine how the parameter affects the bullwhip effect in Figure 6. We can observe that $k$ is an important factor to affect 


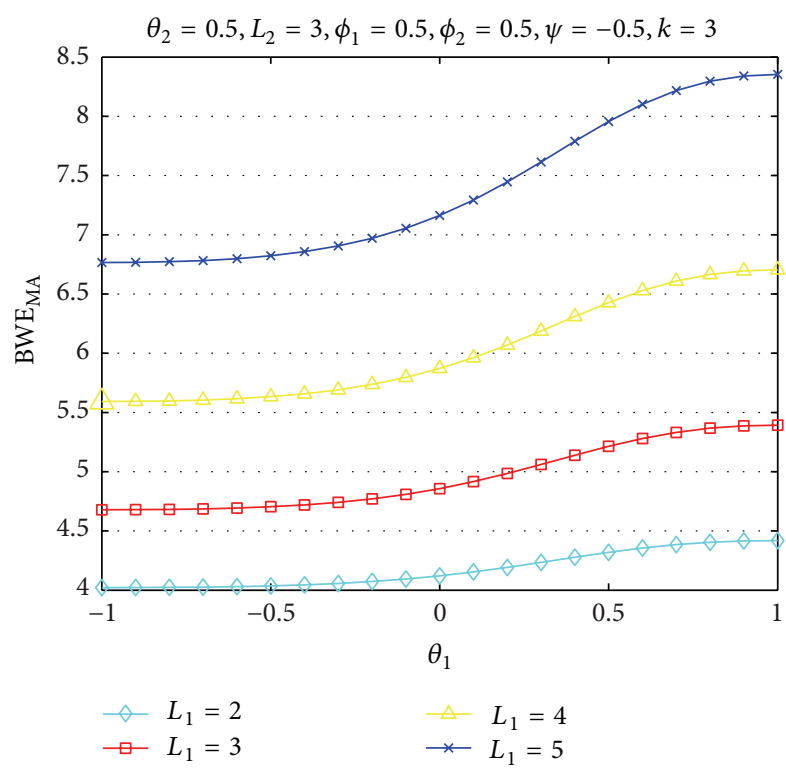

FIGURE 5: Impact of $\theta_{1}$ on bullwhip effect for different $L_{1}$ under the MA.

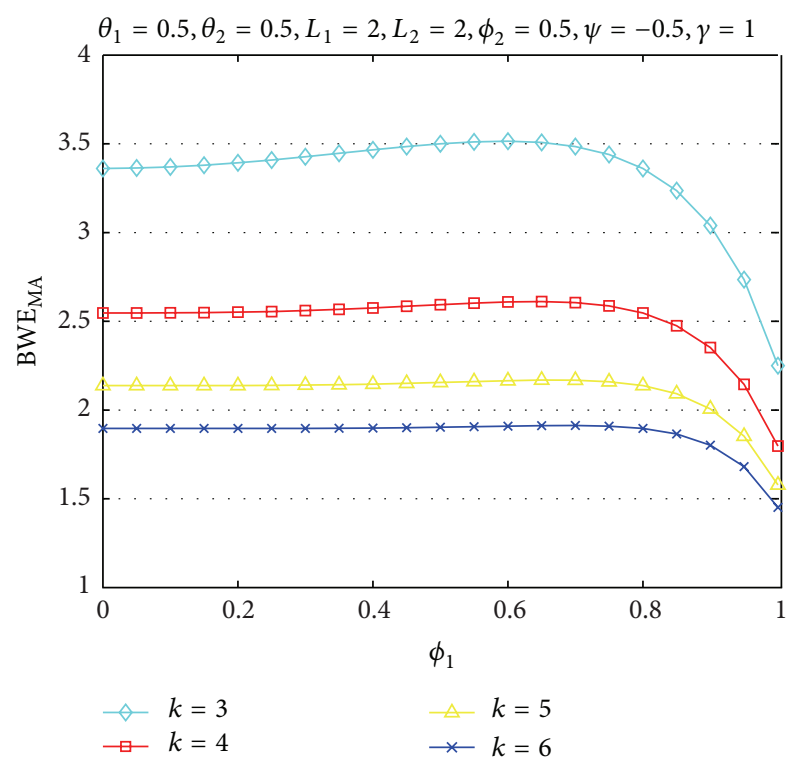

FIGURE 6: Impact of $\phi_{1}$ on the bullwhip effect for different $k$ under the MA.

the bullwhip effect, the greater $k$ can lead to the less bullwhip effect.

Figure 7 investigates how parameters $\gamma$ and $\psi$ affect the bullwhip effect when we set $\theta_{1}=0.5, \theta_{2}=0.5, L_{1}=2$, $L_{2}=2, \phi_{1}=0.5, \phi_{2}=0.5$, and $k=3$. The bullwhip effect increases firstly, and it reaches the maximum number when $\gamma=1$, then decreases with the increase of $\gamma$. The phenomenon illustrates that the bullwhip effect is stronger when the volatility of demand between two retailers is more consistent. Specially, the bullwhip effect attains a maximum when two retailers have the same volatility of demand. For the

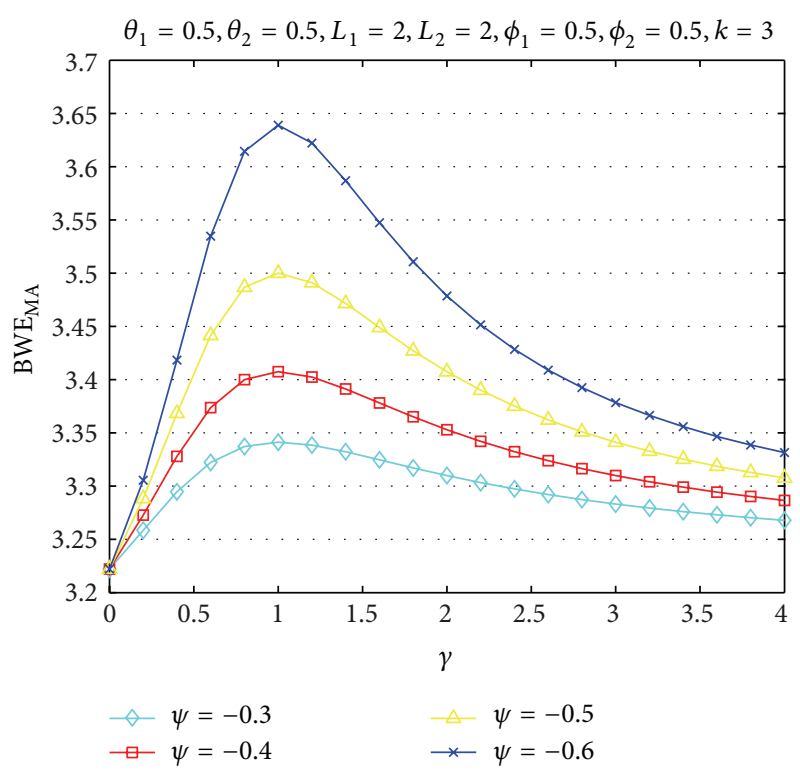

FIGURE 7: Impact of $\gamma$ on bullwhip effect for different $\psi$ under the MA.

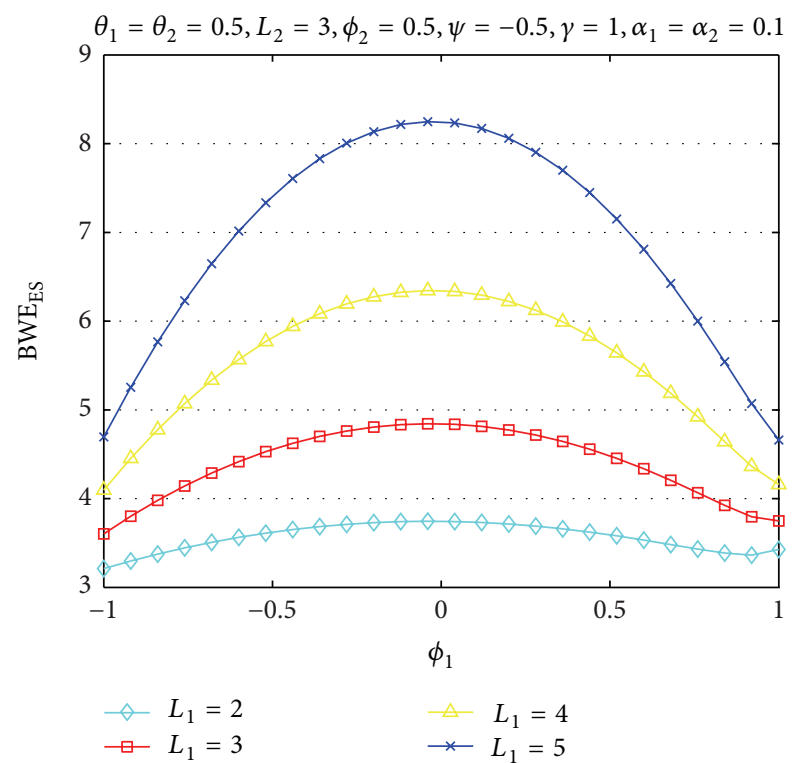

FIGURE 8: Impact of $\phi_{1}$ on the bullwhip effect for different $L_{1}$ under the ES.

correlative coefficient of demand between two retailers, the larger it is the stronger the bullwhip effect is. The conclusion is different from the conclusion under the MMSE forecasting method. In proportion, this phenomenon indicates that the intense competition between two retailers can increase the bullwhip effect.

4.3. The Effect of Parameters on the Bullwhip Effect under the ES. Figures 8-11 simulate the expression of the bullwhip effect under ES forecasting method to illustrate the impact of parameters on the bullwhip effect. For the ES forecasting 


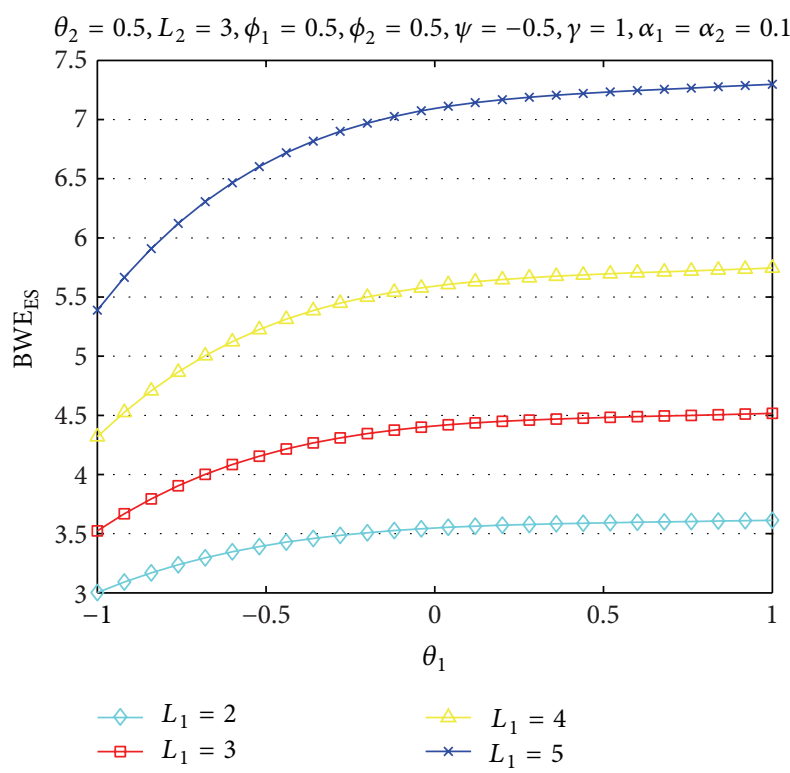

FIGURE 9: Impact of $\theta_{1}$ on bullwhip effect for different $L_{1}$ under the ES.

method, we add the analysis for smoothing exponents. In Figure 8, we set $\theta_{1}=\theta_{2}=0.5, L_{2}=3, \phi_{2}=0.5, \psi=-0.5$, $\gamma=1, \alpha_{1}=\alpha_{2}=0.1$, and vary $\phi_{1}$ from -1 to 1 for different $L_{1}$. The bullwhip effect increases firstly to the maximum value, and then decreases with the increase of $\phi_{1}$. We observe that the greater $L_{1}$ is, the less the bullwhip effect when we fix other parameters, this result is different from cases under MMSE or MA forecasting method.

Figure 9 shows the impact of $\theta_{1}$ on the bullwhip effect when we set $\theta_{2}=0.5, L_{2}=3, \phi_{1}=\phi_{2}=0.5, \psi=-0.5$, $\gamma=1$, and $\alpha_{1}=\alpha_{2}=0.1$. The bullwhip effect increases slowly all the time with the increase of $\theta_{1}$. And in this situation, we shift the lead-time of retailer 1 , and then the bullwhip effect becomes great with the increase of $L_{1}$. This result is the same as the situation under the MA forecasting method.

We shift the smoothing exponent of retailer 1 to indicate its impact on the bullwhip effect in Figure 10, and we observe the bullwhip effect as it grows to be greater with the increase of $\alpha_{1}$.

Figure 11 investigates how parameters $\gamma$ and $\psi$ affect the bullwhip affect under the ES forecasting method when we set $\theta_{1}=\theta_{2}=0.5, L_{1}=L_{2}=3, \phi_{1}=\phi_{2}=0.5, \alpha_{1}=\alpha_{2}=0.1$. The bullwhip effect increases firstly, and it reaches the maximum number when $\gamma=1$, then decreases with the increase of $\gamma$. The phenomenon illustrates that the bullwhip effect is stronger when the volatility of demand between two retailers is more consistent. Specially, the bullwhip effect attains a maximum when two retailers have the same volatility of demand. For the correlative coefficient of demand between two retailers, the larger it is, the stronger the bullwhip effect is. The conclusion is the same as the conclusion under the MMSE forecasting method.

4.4. The Comparison of Three Forecasting Methods. To compare bullwhip effects under three forecasting methods, we

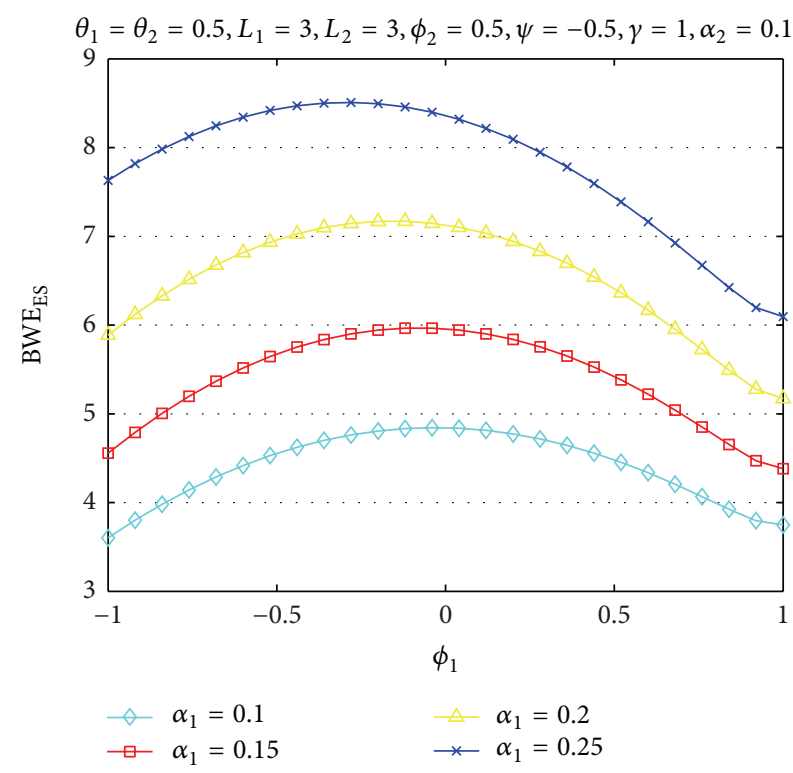

FIGURE 10: Impact of $\phi_{1}$ on the bullwhip effect for different $\alpha_{1}$ under the ES.

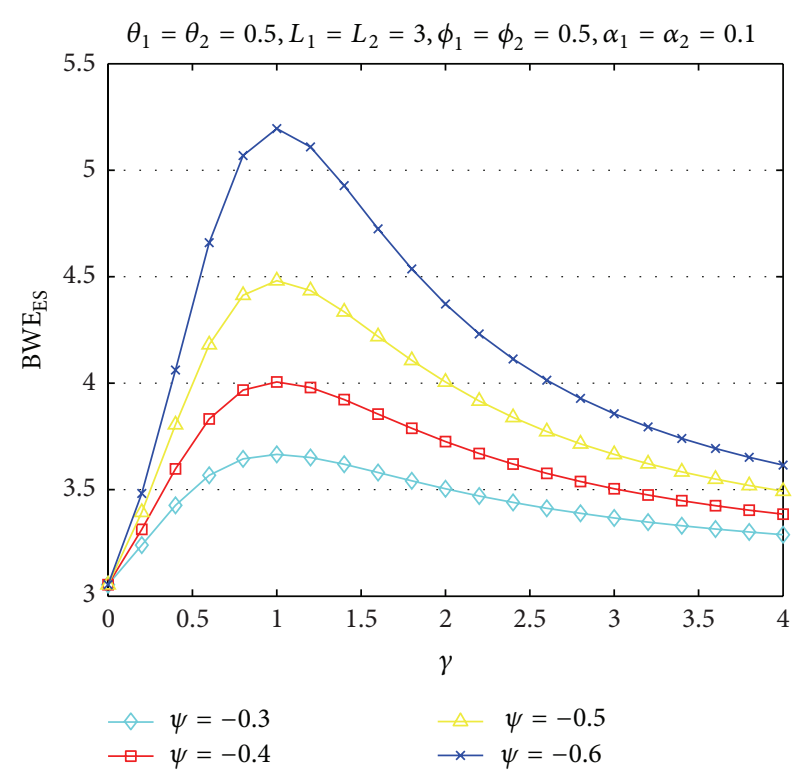

FIGURE 11: Impact of $\gamma$ on bullwhip effect for different $\psi$ under the ES.

have to select appropriate $k, \alpha_{1}$, and $\alpha_{2}$. According to Zhang [12], the MA and ES forecasting methods have the same average date age $((k+1) / 2)$, when we set $\alpha_{1}=\alpha_{2}=2 /(k+1)$ Figures 12-17 depict the comparison of the bullwhip effect among the MMSE, MA, and ES forecasting methods with different date ages, respectively. Then those figures illustrate which one is the best forecasting method for decreasing the bullwhip effect in different conditions.

From Figures 12-14, we observe that $\mathrm{BWE}_{\mathrm{ES}}$ will always be higher than $\mathrm{BWE}_{\mathrm{MA}}$ whatever $\psi$ is as long as $\alpha_{1}=\alpha_{2}=2 /(k+$ $1)$. $\mathrm{BWE}_{\mathrm{MA}}$ and $\mathrm{BWE}_{\mathrm{ES}}$ get lower gradually with the increase of $k$ or with the decrease of $\alpha_{1}$ and $\alpha_{2}$. We set $k=4$, and 


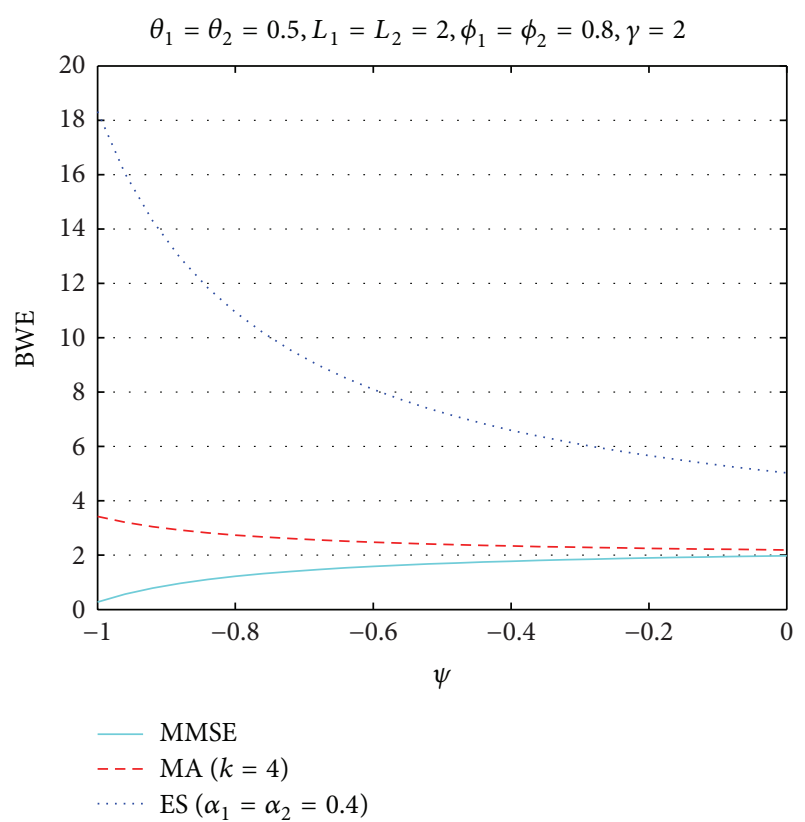

FIGURE 12: Comparison of three forecasting methods by varying $\psi$ $(k=4)$.

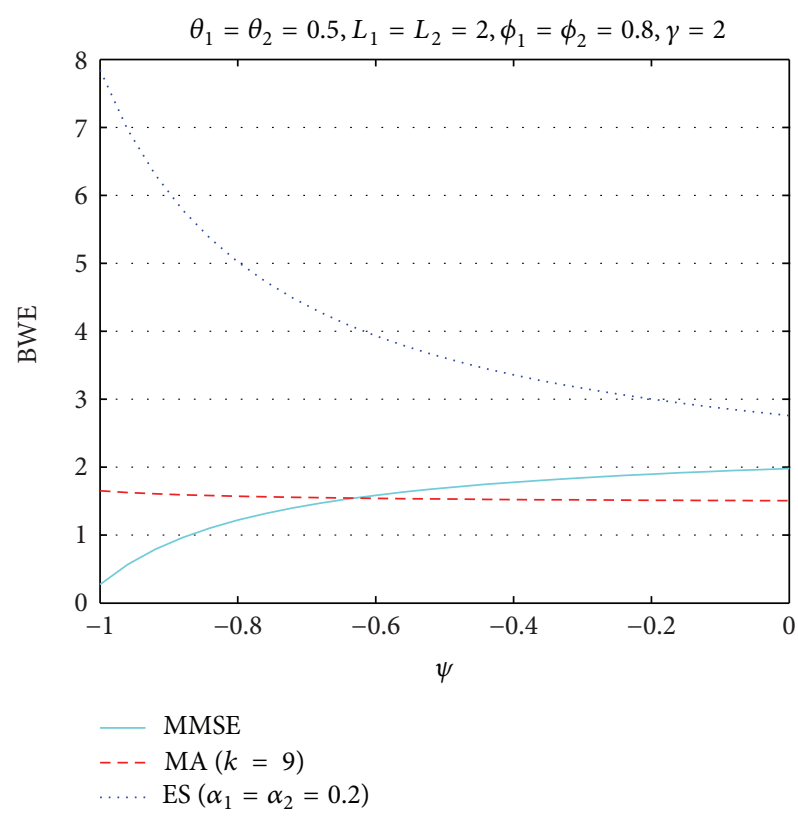

FIGURE 13: Comparison of three forecasting methods by varying $\psi$ $(k=9)$.

$\alpha_{1}=\alpha_{2}=0.4$ and fix other parameters in Figure 12, and $\mathrm{BWE}_{\mathrm{MMSE}}$ is lower than $\mathrm{BWE}_{\mathrm{MA}}$ and $\mathrm{BWE}_{\mathrm{ES}}$ whatever $\psi$ is. It means that the MMSE forecasting method is the best to forecast lead-time demand in this situation. In Figure 13, let $k=9, \alpha_{1}=\alpha_{2}=0.2, \mathrm{BWE}_{\mathrm{MMSE}}$ is lower than $\mathrm{BWE}_{\mathrm{MA}}$ when $\psi$ is smaller than a certain value, $\mathrm{BWE}_{\mathrm{MMSE}}$ is higher than $\mathrm{BWE}_{\mathrm{MA}}$ when $\psi$ is larger than that certain value, and $\mathrm{BWE}_{\mathrm{MMSE}}$ is lower than $\mathrm{BWE}_{\mathrm{ES}}$ whatever $\psi$ is. The conclusion means that the MMES method is the best when

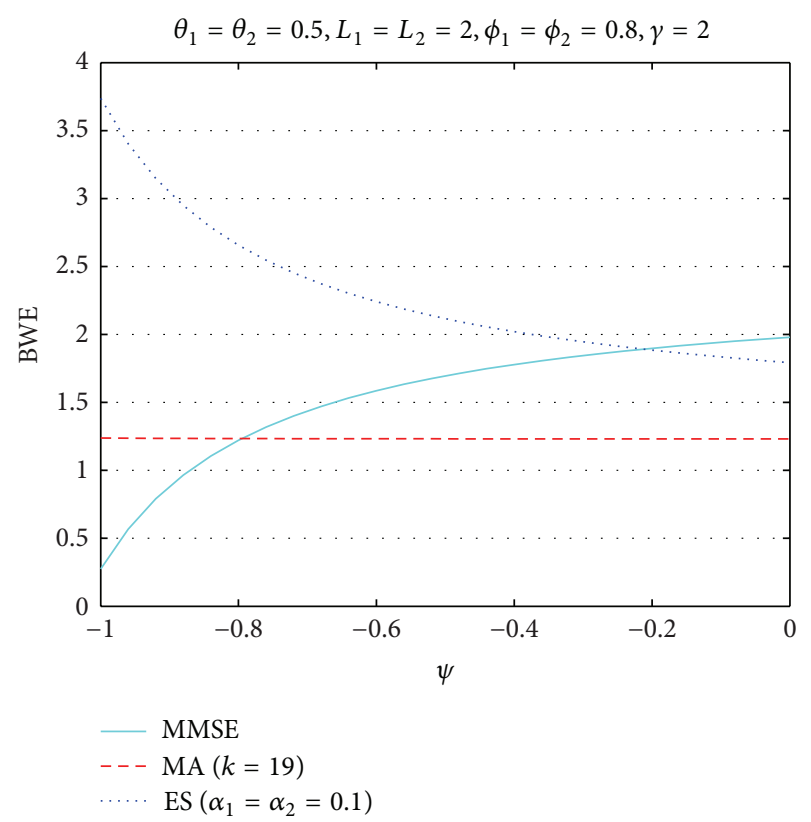

FIGURE 14: Comparison of three forecasting methods by varying $\psi$ $(k=19)$.

the market has fierce competition, and the MA method is the best when the market competition is not hot. In Figure 14, let $k=19, \alpha_{1}=\alpha_{2}=0.1, \mathrm{BWE}_{\mathrm{MMSE}}$ is lower than $\mathrm{BWE}_{\mathrm{MA}}$ when $\psi$ is smaller than a certain value, $\mathrm{BWE}_{\mathrm{MMSE}}$ is higher than $\mathrm{BWE}_{\mathrm{MA}}$ when $\psi$ is larger than that certain value. And $\mathrm{BWE}_{\mathrm{MMSE}}$ is higher than $\mathrm{BWE}_{\mathrm{ES}}$ when $\psi$ is larger than another certain value. It reveals that the MMES method is the best when the market has fierce competition, and the MA method is the best when the market competition is not so hot, and the MMSE method is the worst when the market has little competition.

From Figures $15-17$, we observe that $\mathrm{BWE}_{\mathrm{MA}}$ is always higher than $\mathrm{BWE}_{\mathrm{ES}}$ whatever $\gamma$ is as long as $\alpha_{1}=\alpha_{2}=2 /(k+$ $1)$. $\mathrm{BWE}_{\mathrm{MA}}$ and $\mathrm{BWE}_{\mathrm{ES}}$ get lower gradually with the increase of $k$ or with the decrease of $\alpha_{1}$ and $\alpha_{2}$. We set $k=4, \alpha_{1}=$ $\alpha_{2}=0.4$ and fix other parameters in Figure 15, and BWE $\mathrm{BMSE}_{1}$ is lower than $\mathrm{BWE}_{\mathrm{MA}}$ and $\mathrm{BWE}_{\mathrm{ES}}$ whatever $\gamma$ is. It means that the MMSE forecasting method is the best to forecast leadtime demand whatever the consistency of demand volatility between two retailers is.

In Figure 16, let $k=9, \alpha_{1}=\alpha_{2}=0.2$, BWE $\mathrm{MMSE}_{\mathrm{M}}$ is lower than $\mathrm{BWE}_{\mathrm{MA}}$ when $\gamma$ is smaller than a certain value, $\mathrm{BWE}_{\mathrm{MMSE}}$ is higher than $\mathrm{BWE}_{\mathrm{MA}}$ when $\gamma$ is larger than that certain value, and $\mathrm{BWE}_{\mathrm{MMSE}}$ is lower than $\mathrm{BWE}_{\mathrm{ES}}$ whatever $\gamma$ is. The conclusion means that the MMES method is the best when the volatility of demand between two retailers is more consistent, and the MA, method is the best when the consistency of demand volatility between two retailers is weaker. In Figure 17, let $k=19, \alpha_{1}=\alpha_{2}=0.1$, BWE $\mathrm{MMSE}_{\mathrm{MM}}$ is lower than $\mathrm{BWE}_{\mathrm{ES}}$ when $\gamma$ is smaller than a certain value, $\mathrm{BWE}_{\mathrm{MMSE}}$ is higher than $\mathrm{BWE}_{\mathrm{ES}}$ when $\gamma$ is larger than that certain value, and $\mathrm{BWE}_{\mathrm{MMSE}}$ is higher than $\mathrm{BWE}_{\mathrm{MA}}$ whatever $\gamma$ is. This phenomenon reveals that the MA method is the 


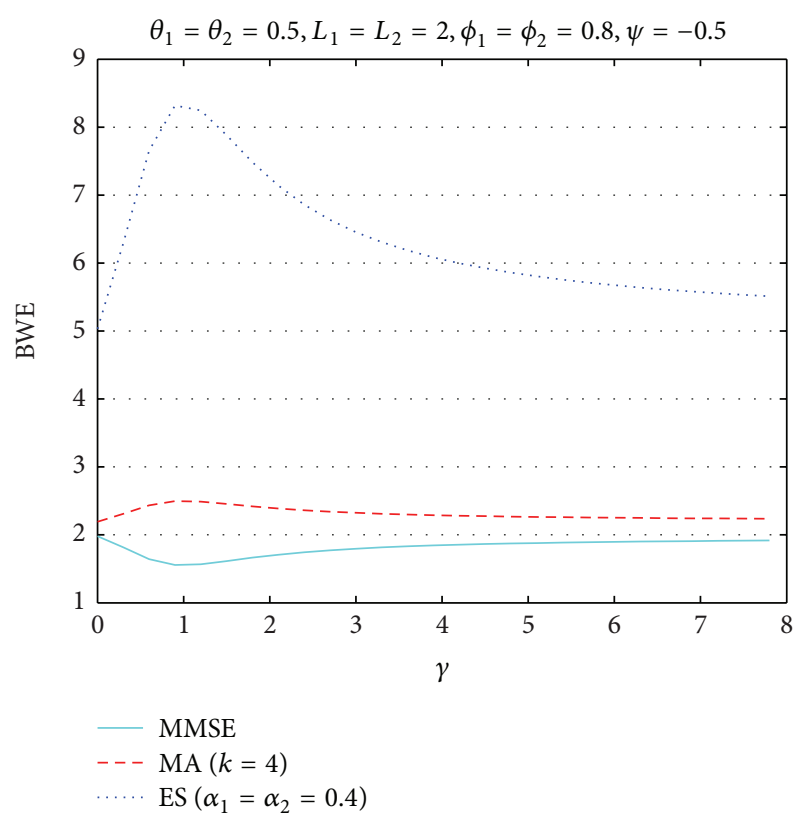

FIGURE 15: Comparison of three forecasting methods by varying $\gamma$ $(k=4)$.

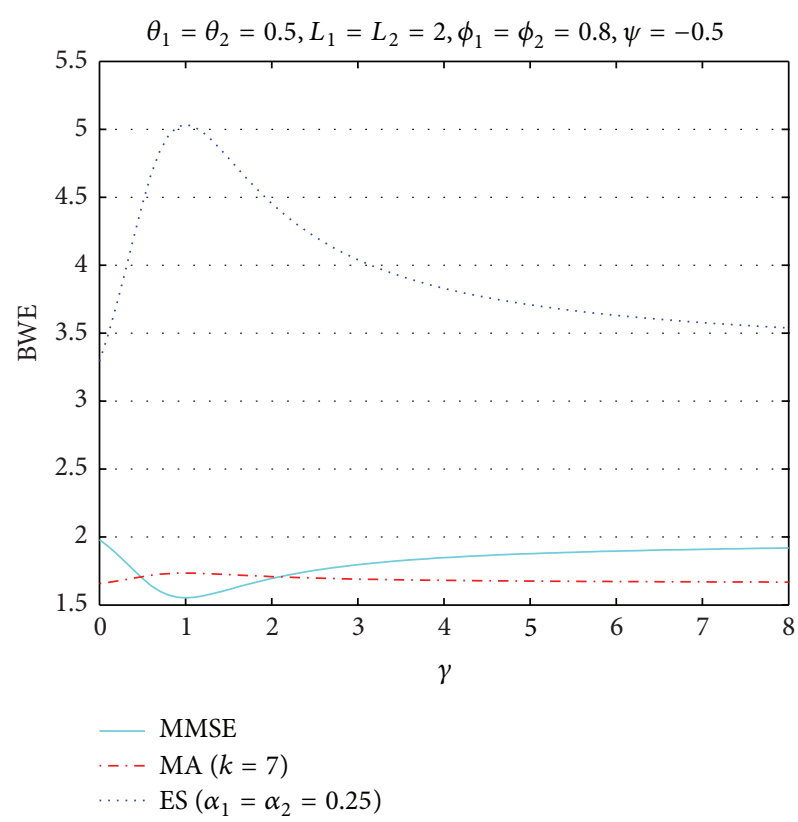

FIGURE 16: Comparison of three forecasting methods by varying $\gamma$ $(k=9)$.

best whatever the consistency of demand volatility between two retailers is, and the MMSE method is the worst when the consistency of demand volatility between two retailers is weaker.

\section{Conclusions}

In this research, a new supply chain model containing two retailers which both followed the $\operatorname{ARMA}(1,1)$ demand

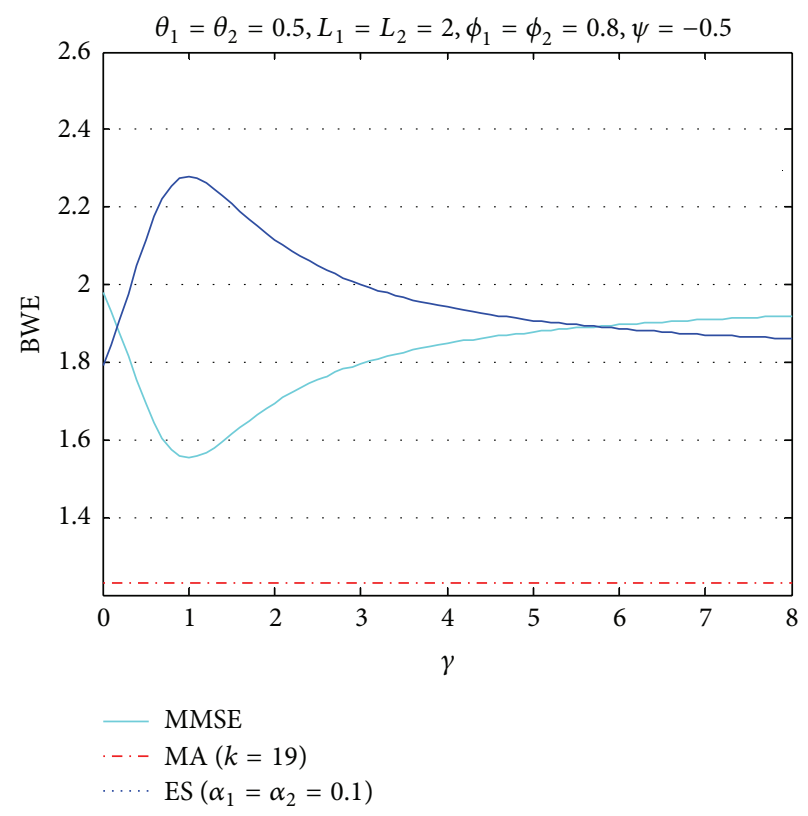

FIGURE 17: Comparison of three forecasting methods by varying $\gamma$ $(k=19)$.

process and employed the order-up-to stock policy was established. The bullwhip effect was measured under the MMSE, MA, and ES forecasting methods respectively. For three bullwhip effect expressions, we investigated the effect of lead-times, autoregressive coefficients, moving average parameters, and the correlation coefficients between two retailers on the bullwhip effect.

Besides those important sources which are pointed out by Lee et al. $[4,5]$, market competition and the consistency of demand volatility between two retailers are also two important factors leading to the bullwhip effect. The results show that the forecasting methods play an important role in determining the impact of those factors on the bullwhip effect. If the MMSE or MA forecasting method is used, shortening lead-time does not always reduce the bullwhip effect when the demand autocorrelation is varying. But, shortening leadtime has the most significant impact on reducing the bullwhip effect when the ES method is used to forecast demand. Under the MA or ES method, average date age has the significant impact on the bullwhip effect, the greater it is the weaker the bullwhip is. Market competition is proportional to the bullwhip effect when the MA or ES method is used, and it is inversely proportional to the bullwhip effect when the MMSE method is used. The consistency of demand volatility between two retailers is inversely proportional to the bullwhip effect when the MA or ES method is used, and it is proportional to the bullwhip effect when the MMSE method is used.

From a managerial perspective, the findings suggest that managers cannot reduce the bullwhip effect by shortening the lead-time blindly. So, managers should learn more knowledge of the basic demand models and different forecasting methods. The MMSE method is always the best among three methods if only the MA and ES method have the shorter 
average date age. The MA method is always better than the ES method whatever the average date age is. But, the bullwhip effect under the MA and ES methods will be receded with the increase of average date age. Also, we know that the MA or ES method may perform better than the MMSE method because they are more flexible and adapt better to the changing structures of the demand when the demand structure is not well specified or shifts over time. Then, the MA or ES method may be better than the MMSE method.

Quantifying the bullwhip effect and investigating its behavior are helpful in the allocation of efforts for mitigating the influence of the bullwhip effect in supply chains. This paper can be continuous in several directions that are likely to enhance our understanding of how demand signals are transmitted along the supply chain system. First, more general inventory policies can be studied. The simple orderup-to inventory policy can be misleading when an obvious fixed ordering cost exists. So, the study on the bullwhip effect for the general $(s, S)$ policy would have more practical significance. Second, more factors can be used for evaluating three forecasting methods. In this paper, the bullwhip effect as the only factor is the standard to estimate various forecasting methods. Managers may pay more attention to the inventory cost in practice, so researches on the impact of parameters for the inventory cost should be interesting.

\section{Appendix}

\section{Proofs}

$$
\begin{gathered}
\operatorname{Var}\left(D_{1, t-1}\right)=\operatorname{Var}\left(D_{1, t-2}\right)=\operatorname{Var}\left(D_{1}\right), \\
\operatorname{Var}\left(D_{2, t-1}\right)=\operatorname{Var}\left(D_{2, t-2}\right)=\operatorname{Var}\left(D_{2}\right), \\
\operatorname{Var}\left(\varepsilon_{1, t-1}\right)=\operatorname{Var}\left(\varepsilon_{1, t-2}\right)=\frac{1-\phi_{1}^{2}}{1+\theta_{1}^{2}-2 \phi_{1} \theta_{1}} \operatorname{Var}\left(D_{1}\right), \\
\operatorname{Var}\left(\varepsilon_{2, t-1}\right)=\operatorname{Var}\left(\varepsilon_{2, t-2}\right)=\frac{1-\phi_{2}^{2}}{1+\theta_{2}^{2}-2 \phi_{2} \theta_{2}} \operatorname{Var}\left(D_{2}\right) .
\end{gathered}
$$

According to Feng and Ma [13], we have

$$
\begin{aligned}
& \operatorname{Cov}\left(D_{1, t-1}, D_{1, t-k-1}\right) \\
& =\phi_{1}^{k-1}\left(\frac{\left(\phi_{1}-\theta_{1}\right)\left(1-\phi_{1} \theta_{1}\right)}{1+\theta_{1}^{2}-2 \phi_{1} \theta_{1}}\right) \operatorname{Var}\left(D_{1, t}\right), \\
& \operatorname{Cov}\left(D_{2, t-1}, D_{2, t-k-1}\right) \\
& =\phi_{2}^{k-1}\left(\frac{\left(\phi_{2}-\theta_{2}\right)\left(1-\phi_{2} \theta_{2}\right)}{1+\theta_{2}^{2}-2 \phi_{2} \theta_{2}}\right) \operatorname{Var}\left(D_{2, t}\right) .
\end{aligned}
$$

After iteration computation, we have

$$
\begin{aligned}
D_{1, t-1}= & \left(1+\phi_{1}+\cdots+\phi_{1}^{k-1}\right) \delta_{1}+\phi_{1}^{k} D_{1, t-k-1} \\
& +\left(\varepsilon_{1, t-1}+\phi_{1} \varepsilon_{1, t-2}+\cdots+\phi_{1}^{k-1} \varepsilon_{1, t-k}\right) \\
& -\theta_{1}\left(\varepsilon_{1, t-2}+\phi_{1} \varepsilon_{1, t-3}+\cdots+\phi_{1}^{k-1} \varepsilon_{1, t-k-1}\right),
\end{aligned}
$$

so, we can get

$$
\begin{aligned}
& \operatorname{Cov}\left(D_{1, t-1}, D_{2, t-k-1}\right) \\
& \begin{aligned}
&=\operatorname{Cov}((\left.+\phi_{1}+\cdots+\phi_{1}^{k-1}\right) \delta_{1}+\phi_{1}^{k} D_{1, t-k-1} \\
&+\left(\varepsilon_{1, t-1}+\phi_{1} \varepsilon_{1, t-2}+\cdots+\phi_{1}^{k-1} \varepsilon_{1, t-k}\right) \\
&-\theta_{1}\left(\varepsilon_{1, t-2}+\phi_{1} \varepsilon_{1, t-3}+\cdots+\phi_{1}^{k-1} \varepsilon_{1, t-k-1}\right), \\
&\left.D_{2, t-k-1}\right) \\
&=\phi_{1}^{k} \psi \sqrt{\operatorname{Var}\left(D_{1, t}\right) \operatorname{Var}\left(D_{2, t}\right)},
\end{aligned}
\end{aligned}
$$

and we also have

$$
\operatorname{Cov}\left(D_{2, t-1}, D_{1, t-k-1}\right)=\phi_{2}^{k} \psi \sqrt{\operatorname{Var}\left(D_{1, t}\right) \operatorname{Var}\left(D_{2, t}\right)} .
$$

According to Duc et al. [10], we have

$$
\begin{gathered}
\operatorname{Cov}\left(D_{1, t-1}, \varepsilon_{1, t-1}\right)=\operatorname{Var}\left(\varepsilon_{1, t-1}\right), \\
\operatorname{Cov}\left(D_{1, t-1}, \varepsilon_{1, t-2}\right)=\left(\phi_{1}-\theta_{1}\right) \operatorname{Var}\left(\varepsilon_{1, t-1}\right),
\end{gathered}
$$

so, we also have

$$
\begin{gathered}
\operatorname{Cov}\left(D_{2, t-1}, \varepsilon_{2, t-1}\right)=\operatorname{Var}\left(\varepsilon_{2, t-1}\right), \\
\operatorname{Cov}\left(D_{2, t-1}, \varepsilon_{2, t-2}\right)=\left(\phi_{2}-\theta_{2}\right) \operatorname{Var}\left(\varepsilon_{2, t-1}\right) .
\end{gathered}
$$

Proof of Proposition 1. Total order quantity of period $t$ under the MMSE forecasting method is

$$
\begin{aligned}
q_{t}= & \left(\phi_{1} A_{1}+1\right) D_{1, t-1}-\phi_{1} A_{1} D_{1, t-2}-\theta_{1} A_{1} \varepsilon_{1, t-1} \\
& +\theta_{1} A_{1} \varepsilon_{1, t-2}+\left(\phi_{2} A_{2}+1\right) D_{2, t-1} \\
& -\phi_{2} A_{2} D_{2, t-2}-\theta_{2} A_{2} \varepsilon_{2, t-1}+\theta_{2} A_{2} \varepsilon_{2, t-2} .
\end{aligned}
$$

Taking the variance for (A.12), we get

$$
\begin{aligned}
\operatorname{Var}\left(q_{t}\right) & \\
= & \left(\phi_{1} A_{1}+1\right)^{2} \operatorname{Var}\left(D_{1, t-1}\right)+\left(\phi_{1} A_{1}\right)^{2} \operatorname{Var}\left(D_{1, t-2}\right) \\
& +\left(\theta_{1} A_{1}\right)^{2} \operatorname{Var}\left(\varepsilon_{1, t-1}\right)+\left(\theta_{1} A_{1}\right)^{2} \operatorname{Var}\left(\varepsilon_{1, t-2}\right) \\
& +\left(\phi_{2} A_{2}+1\right)^{2} \operatorname{Var}\left(D_{2, t-1}\right)+\left(\phi_{2} A_{2}\right)^{2} \operatorname{Var}\left(D_{2, t-2}\right) \\
& +\left(\theta_{2} A_{2}\right)^{2} \operatorname{Var}\left(\varepsilon_{2, t-1}\right)+\left(\theta_{2} A_{2}\right)^{2} \operatorname{Var}\left(\varepsilon_{2, t-2}\right) \\
& -2 \phi_{1} A_{1}\left(\phi_{1} A_{1}+1\right) \operatorname{Cov}\left(D_{1, t-1}, D_{1, t-2}\right) \\
& -2 \theta_{1} A_{1}\left(\phi_{1} A_{1}+1\right) \operatorname{Cov}\left(D_{1, t-1}, \varepsilon_{1, t-1}\right) \\
& +2 \theta_{1} A_{1}\left(\phi_{1} A_{1}+1\right) \operatorname{Cov}\left(D_{1, t-1}, \varepsilon_{1, t-2}\right) \\
& +2\left(\phi_{1} A_{1}+1\right)\left(\phi_{2} A_{2}+1\right) \operatorname{Cov}\left(D_{1, t-1}, D_{2, t-1}\right) \\
& -2 \phi_{2} A_{2}\left(\phi_{1} A_{1}+1\right) \operatorname{Cov}\left(D_{1, t-1}, D_{2, t-2}\right) \\
& -2 \phi_{1} \theta_{1} A_{1}^{2} \operatorname{Cov}\left(D_{1, t-2}, \varepsilon_{1, t-2}\right) \\
& -2 \phi_{1} A_{1}\left(\phi_{2} A_{2}+1\right) \operatorname{Cov}\left(D_{1, t-2}, D_{2, t-1}\right)
\end{aligned}
$$




$$
\begin{aligned}
& +2 \phi_{1} \phi_{2} A_{1} A_{2} \operatorname{Cov}\left(D_{1, t-2}, D_{2, t-2}\right) \\
& -2 \phi_{2} A_{2}\left(\phi_{2} A_{2}+1\right) \operatorname{Cov}\left(D_{2, t-1}, D_{2, t-2}\right) \\
& -2 \theta_{2} A_{2}\left(\phi_{2} A_{2}+1\right) \operatorname{Cov}\left(D_{2, t-1}, \varepsilon_{2, t-1}\right) \\
& +2 \theta_{2} A_{2}\left(\phi_{2} A_{2}+1\right) \operatorname{Cov}\left(D_{2, t-1}, \varepsilon_{2, t-2}\right) \\
& -2 \phi_{2} \theta_{2} A_{2}^{2} \operatorname{Cov}\left(D_{2, t-2}, \varepsilon_{2, t-2}\right) .
\end{aligned}
$$

Bring (A.1)-(A.12) into (A.14) and take the simplification, then we can get

$\operatorname{Var}\left(q_{t}\right)$

$$
\begin{aligned}
=( & \left(\phi_{1} A_{1}+1\right)^{2}+\left(\phi_{1} A_{1}\right)^{2}+\frac{2\left(\theta_{1} A_{1}\right)^{2}\left(1-\phi_{1}^{2}\right)}{1+\theta_{1}^{2}-2 \phi_{1} \theta_{1}} \\
- & \frac{2 \phi_{1} A_{1}\left(\phi_{1} A_{1}+1\right)\left(\phi_{1}-\theta_{1}\right)\left(1-\phi_{1} \theta_{1}\right)}{1+\theta_{1}^{2}-2 \phi_{1} \theta_{1}} \\
+ & \frac{2 \theta_{1} A_{1}\left(\phi_{1} A_{1}+1\right)\left(\phi_{1}-\theta_{1}-1\right)\left(1-\phi_{1}^{2}\right)}{1+\theta_{1}^{2}-2 \phi_{1} \theta_{1}} \\
- & \left.\frac{2 \phi_{1} \theta_{1} A_{1}^{2}\left(1-\phi_{1}^{2}\right)}{1+\theta_{1}^{2}-2 \phi_{1} \theta_{1}}\right) \operatorname{Var}\left(D_{1}\right) \\
+( & \left(\phi_{2} A_{2}+1\right)^{2}+\left(\phi_{2} A_{2}\right)^{2}+\frac{2\left(\theta_{2} A_{2}\right)^{2}\left(1-\phi_{2}^{2}\right)}{1+\theta_{2}^{2}-2 \phi_{2} \theta_{2}} \\
& -\frac{2 \phi_{2} A_{2}\left(\phi_{2} A_{2}+1\right)\left(\phi_{2}-\theta_{2}\right)\left(1-\phi_{2} \theta_{2}\right)}{1+\theta_{2}^{2}-2 \phi_{2} \theta_{2}} \\
& +\frac{2 \theta_{2} A_{2}\left(\phi_{2} A_{2}+1\right)\left(\phi_{2}-\theta_{2}-1\right)\left(1-\phi_{2}^{2}\right)}{1+\theta_{2}^{2}-2 \phi_{2} \theta_{2}} \\
& \left.+\frac{2 \phi_{2} \theta_{2} A_{2}^{2}\left(1-\phi_{2}^{2}\right)}{1+\theta_{2}^{2}-2 \phi_{2} \theta_{2}}\right) \operatorname{Var}\left(D_{2}\right) \\
+2( & \left(\phi_{1} A_{1}+1\right)\left(\phi_{2} A_{2}+1\right)-\phi_{2} A_{2}\left(\phi_{1} A_{1}+1\right) \phi_{1} \\
& \left.-\phi_{1} A_{1}\left(\phi_{2} A_{2}+1\right) \phi_{2} A_{2}\right) \psi \sqrt{\operatorname{Var}\left(D_{1, t}\right) \operatorname{Var}\left(D_{2, t}\right)} . \\
+ &
\end{aligned}
$$

This completes the Proof for Proposition 1.

Proof of Proposition 2. Total order quantity of period $t$ under the MA forecasting method is

$$
\begin{aligned}
q_{t}= & q_{1, t}+q_{2, t}=\left(1+\frac{L_{1}}{k}\right) D_{1, t-1}-\frac{L_{1}}{k} D_{1, t-k-1} \\
& +\left(1+\frac{L_{2}}{k}\right) D_{2, t-1}-\frac{L_{2}}{k} D_{2, t-k-1} .
\end{aligned}
$$

Taking the variance for (A.16), we get

$\operatorname{Var}\left(q_{t}\right)$

$$
\begin{aligned}
= & \left(1+\frac{L_{1}}{k}\right)^{2} \operatorname{Var}\left(D_{1, t-1}\right)+\left(\frac{L_{1}}{k}\right)^{2} \operatorname{Var}\left(D_{1, t-k-1}\right) \\
& +\left(1+\frac{L_{2}}{k}\right)^{2} \operatorname{Var}\left(D_{2, t-1}\right)+\left(\frac{L_{2}}{k}\right)^{2} \operatorname{Var}\left(D_{2, t-k-1}\right) \\
& -2 \frac{L_{1}}{k}\left(1+\frac{L_{1}}{k}\right) \operatorname{Cov}\left(D_{1, t-1}, D_{1, t-k-1}\right)+2\left(1+\frac{L_{1}}{k}\right) \\
& \times\left(1+\frac{L_{2}}{k}\right) \operatorname{Cov}\left(D_{1, t-1}, D_{2, t-1}\right)-2 \frac{L_{2}}{k}\left(1+\frac{L_{1}}{k}\right) \\
& \times \operatorname{Cov}\left(D_{1, t-1}, D_{2, t-k-1}\right) \\
& -2 \frac{L_{1}}{k}\left(1+\frac{L_{2}}{k}\right) \operatorname{Cov}\left(D_{1, t-k-1}, D_{2, t-1}\right)+2 \frac{L_{1} L_{2}}{k^{2}} \\
& \times \operatorname{Cov}\left(D_{1, t-k-1}, D_{2, t-k-1}\right) \\
& -2 \frac{L_{2}}{k}\left(1+\frac{L_{2}}{k}\right) \operatorname{Cov}\left(D_{2, t-1}, D_{2, t-k-1}\right) .
\end{aligned}
$$

Bring (A.1)-(A.2) and (A.5)-(A.9) into (A.17), then take the simplification, and we can get

$\operatorname{Var}\left(q_{t}\right)$

$$
\begin{aligned}
& =\left(\left(1+\frac{L_{1}}{k}\right)^{2}+\left(\frac{L_{1}}{k}\right)^{2}-2 \frac{L_{1}}{k}\left(1+\frac{L_{1}}{k}\right)\right. \\
& \left.\times\left(\frac{\left(\phi_{1}-\theta_{1}\right)\left(1-\phi_{1} \theta_{1}\right)}{1+\theta_{1}^{2}-2 \phi_{1} \theta_{1}}\right) \phi_{1}^{k-1}\right) \operatorname{Var}\left(D_{1, t}\right) \\
& +\left(\left(1+\frac{L_{2}}{k}\right)^{2}+\left(\frac{L_{2}}{k}\right)^{2}-2 \frac{L_{2}}{k}\left(1+\frac{L_{2}}{k}\right)\right. \\
& \left.\quad \times\left(\frac{\left(\phi_{2}-\theta_{2}\right)\left(1-\phi_{2} \theta_{2}\right)}{1+\theta_{2}^{2}-2 \phi_{2} \theta_{2}}\right) \phi_{2}^{k-1}\right) \operatorname{Var}\left(D_{2, t}\right) \\
& +\left(2\left(1+\frac{L_{1}}{k}\right)\left(1+\frac{L_{2}}{k}\right)-2 \frac{L_{2}}{k}\left(1+\frac{L_{1}}{k}\right) \phi_{1}^{k}\right. \\
& \left.\quad-2 \frac{L_{1}}{k}\left(1+\frac{L_{2}}{k}\right) \phi_{2}^{k}+2 \frac{L_{1} L_{2}}{k^{2}}\right) \\
& \times \psi \sqrt{\operatorname{Var}\left(D_{1, t}\right) \operatorname{Var}\left(D_{2, t}\right)} .
\end{aligned}
$$

This completes the Proof for Proposition 2.

Proof of Proposition 3. Total order quantity of period $t$ under the MA forecasting method is

$$
\begin{aligned}
q_{t}= & \left(1+\alpha_{1} L_{1}\right) D_{1, t}-\alpha_{1} L_{1} \widehat{D}_{1, t} \\
& +\left(1+\alpha_{2} L_{2}\right) D_{2, t}-\alpha_{2} L_{2} \widehat{D}_{2, t}
\end{aligned}
$$


Taking the variance for (A.19), we get

$$
\begin{aligned}
\operatorname{Var} & \left(q_{t}\right) \\
= & \left(1+\alpha_{1} L_{1}\right)^{2} \operatorname{Var}\left(D_{1, t}\right)+\left(\alpha_{1} L_{1}\right)^{2} \operatorname{Var}\left(\widehat{D}_{1, t}\right) \\
& +\left(1+\alpha_{2} L_{2}\right)^{2} \operatorname{Var}\left(D_{2, t}\right)+\left(\alpha_{2} L_{2}\right)^{2} \operatorname{Var}\left(\widehat{D}_{2, t}\right) \\
& -2 \alpha_{1} L_{1}\left(1+\alpha_{1} L_{1}\right) \operatorname{Cov}\left(D_{1, t}, \widehat{D}_{1, t}\right)+2\left(1+\alpha_{1} L_{1}\right) \\
& \times\left(1+\alpha_{2} L_{2}\right) \operatorname{Cov}\left(D_{1, t}, D_{2, t}\right)-2 \alpha_{2} L_{2}\left(1+\alpha_{1} L_{1}\right) \\
& \times \operatorname{Cov}\left(D_{1, t}, \widehat{D}_{2, t}\right) \\
& -2 \alpha_{1} L_{1}\left(1+\alpha_{2} L_{2}\right) \operatorname{Cov}\left(\widehat{D}_{1, t}, D_{2, t}\right) \\
& +2 \alpha_{1} L_{1} \alpha_{2} L_{2} \operatorname{Cov}\left(\widehat{D}_{1, t}, \widehat{D}_{2, t}\right)-2 \alpha_{2} L_{2}\left(1+\alpha_{2} L_{2}\right) \\
& \times \operatorname{Cov}\left(D_{2, t}, \widehat{D}_{2, t}\right) .
\end{aligned}
$$

From Zhang [12], we have

$$
\begin{gathered}
\widehat{D}_{1, t}=\sum_{i=0}^{\infty} \alpha_{1}\left(1-\alpha_{1}\right)^{i} D_{1, t-i-1}, \\
\operatorname{Var}\left(\widehat{D}_{1, t}\right)=\frac{1+\left(1-\alpha_{1}\right) \phi_{1}}{\alpha_{1}\left(2-\alpha_{1}\right)\left(1-\left(1-\alpha_{1}\right) \phi_{1}\right)} \operatorname{Var}\left(D_{1, t}\right), \\
\operatorname{Var}\left(\widehat{D}_{2, t}\right)=\frac{1+\left(1-\alpha_{2}\right) \phi_{2}}{\alpha_{2}\left(2-\alpha_{2}\right)\left(1-\left(1-\alpha_{2}\right) \phi_{2}\right)} \operatorname{Var}\left(D_{2, t}\right) .
\end{gathered}
$$

According to (A.21), we can get

$$
\begin{aligned}
& \operatorname{Cov}\left(D_{1, t}, \widehat{D}_{1, t}\right) \\
& =\operatorname{Cov}\left(D_{1, t}, \sum_{i=0}^{\infty} \alpha_{1}\left(1-\alpha_{1}\right)^{i} D_{1, t-i-1}\right) \\
& =\alpha_{1} \sum_{i=0}^{\infty}\left(1-\alpha_{1}\right)^{i} \operatorname{Cov}\left(D_{1, t}, D_{1, t-i-1}\right),
\end{aligned}
$$

and according to (A.5), (A.24) equals to

$$
\begin{aligned}
& \operatorname{Cov}\left(D_{1, t}, \widehat{D}_{1, t}\right) \\
& =\alpha_{1} \sum_{i=0}^{\infty}\left(1-\alpha_{1}\right)^{i} \phi_{1}^{i}\left(\frac{\left(\phi_{1}-\theta_{1}\right)\left(1-\phi_{1} \theta_{1}\right)}{1+\theta_{1}^{2}-2 \phi_{1} \theta_{1}}\right) \operatorname{Var}\left(D_{1, t}\right) \\
& =\frac{\alpha_{1}\left(\phi_{1}-\theta_{1}\right)\left(1-\phi_{1} \theta_{1}\right)}{\left(1-\phi_{1}\left(1-\alpha_{1}\right)\right)\left(1+\theta_{1}^{2}-2 \phi_{1} \theta_{1}\right)} \operatorname{Var}\left(D_{1, t}\right) .
\end{aligned}
$$

The same, we also have

$$
\begin{aligned}
& \operatorname{Cov}\left(D_{2, t}, \widehat{D}_{2, t}\right) \\
& =\frac{\alpha_{2}\left(\phi_{2}-\theta_{2}\right)\left(1-\phi_{2} \theta_{2}\right)}{\left(1-\phi_{2}\left(1-\alpha_{2}\right)\right)\left(1+\theta_{2}^{2}-2 \phi_{2} \theta_{2}\right)} \operatorname{Var}\left(D_{2, t}\right) .
\end{aligned}
$$

According to (A.21), we can get

$$
\begin{aligned}
& \operatorname{Cov}\left(D_{1, t}, \widehat{D}_{2, t}\right) \\
& =\operatorname{Cov}\left(D_{1, t}, \sum_{i=0}^{\infty} \alpha_{2}\left(1-\alpha_{2}\right)^{i} D_{2, t-i-1}\right) \\
& =\alpha_{2} \sum_{i=0}^{\infty}\left(1-\alpha_{2}\right)^{i} \operatorname{Cov}\left(D_{1, t}, D_{2, t-i-1}\right),
\end{aligned}
$$

and according to (A.9), (A.27) equals to

$$
\begin{aligned}
& \operatorname{Cov}\left(D_{1, t}, \widehat{D}_{2, t}\right) \\
& =\alpha_{2} \sum_{i=0}^{\infty}\left(1-\alpha_{2}\right)^{i} \phi_{1}^{i+1} \psi \sqrt{\operatorname{Var}\left(D_{1, t}\right) \operatorname{Var}\left(D_{2, t}\right)} \\
& =\frac{\alpha_{2} \phi_{1} \psi}{1-\phi_{1}\left(1-\alpha_{2}\right)} \sqrt{\operatorname{Var}\left(D_{1, t}\right) \operatorname{Var}\left(D_{2, t}\right)} .
\end{aligned}
$$

The same, we also have

$$
\operatorname{Cov}\left(D_{2, t}, \widehat{D}_{1, t}\right)=\frac{\alpha_{1} \phi_{2} \psi}{1-\phi_{2}\left(1-\alpha_{1}\right)} \sqrt{\operatorname{Var}\left(D_{1, t}\right) \operatorname{Var}\left(D_{2, t}\right)} .
$$

From (A.21), we also get

$$
\widehat{D}_{1, t}=\sum_{i=0}^{\infty} \alpha_{1}\left(1-\alpha_{1}\right)^{i} D_{1, t-i-1} .
$$

So, we can get

$$
\begin{aligned}
& \operatorname{Cov}\left(\widehat{D}_{1, t}, \widehat{D}_{2, t}\right) \\
& =\operatorname{Cov}\left(\sum_{i=0}^{\infty} \alpha_{1}\left(1-\alpha_{1}\right)^{i} D_{1, t-i-1}, \sum_{j=0}^{\infty} \alpha_{2}\left(1-\alpha_{2}\right)^{j} D_{2, t-j-1}\right) \\
& =\alpha_{1} \alpha_{2} \operatorname{Cov}\left(\sum_{i=0}^{\infty}\left(1-\alpha_{1}\right)^{i} D_{1, t-i-1}, \sum_{j=0}^{\infty}\left(1-\alpha_{2}\right)^{j} D_{2, t-j-1}\right) \\
& =\alpha_{1} \alpha_{2}\left(\sum_{i=0}^{\infty} \sum_{j=i+1}^{\infty}\left(1-\alpha_{1}\right)^{i}\left(1-\alpha_{2}\right)^{j} \phi_{2}^{j-i}\right. \\
& \left.\quad+\sum_{i=0}^{\infty} \sum_{j=0}^{i-1}\left(1-\alpha_{1}\right)^{i}\left(1-\alpha_{2}\right)^{j} \phi_{1}^{i-j}\right) \\
& \times \psi \sqrt{\operatorname{Var}\left(D_{1, t}\right) \operatorname{Var}\left(D_{2, t}\right)}
\end{aligned}
$$




$$
\begin{aligned}
& =\alpha_{1} \alpha_{2}\left(\sum_{i=0}^{\infty} \frac{\left(1-\alpha_{2}\right)^{i+1}\left(1-\alpha_{1}\right)^{i} \phi_{2}}{1-\phi_{2}\left(1-\alpha_{2}\right)}\right. \\
& \left.\quad+\sum_{i=0}^{\infty} \frac{\left(1-\alpha_{1}\right)^{i}\left(1-\alpha_{2}\right) \phi_{1}^{i}\left(1-\left(\left(1-\alpha_{2}\right) / \phi_{1}\right)^{i}\right)}{1-\left(\left(1-\alpha_{2}\right) / \phi_{1}\right)}\right) \\
& =\frac{\phi_{2}\left(1-\alpha_{2}\right)}{\left(1-\left(1-\alpha_{1}\right)\left(1-\alpha_{2}\right)\right)\left(1-\phi_{2}\left(1-\alpha_{2}\right)\right)} \\
& \quad \times \psi \sqrt{\operatorname{Var}\left(D_{1, t}\right) \operatorname{Var}}
\end{aligned}
$$

Bing (A.1)-(A.2), (A.22)-(A.23), (A.28)-(A.29), and (A.31) into (A.20), then take the simplification, and we can get

$$
\begin{aligned}
& \operatorname{Var}\left(q_{t}\right) \\
& =\left(\left(1+\alpha_{1} L_{1}\right)^{2}+\frac{\left(\alpha_{1} L_{1}\right)^{2}\left(1+\left(1-\alpha_{1}\right) \phi_{1}\right)}{\alpha_{1}\left(2-\alpha_{1}\right)\left(1-\left(1-\alpha_{1}\right) \phi_{1}\right)}\right. \\
& \left.-\frac{2 \alpha_{1}^{2} L_{1}\left(1+\alpha_{1} L_{1}\right)\left(\phi_{1}-\theta_{1}\right)\left(1-\phi_{1} \theta_{1}\right)}{\left(1-\phi_{1}\left(1-\alpha_{1}\right)\right)\left(1+\theta_{1}^{2}-2 \phi_{1} \theta_{1}\right)}\right) \\
& \times \operatorname{Var}\left(D_{1, t}\right) \\
& +\left(\left(1+\alpha_{2} L_{2}\right)^{2}\right. \\
& +\frac{\left(\alpha_{2} L_{2}\right)^{2}\left(1+\left(1-\alpha_{2}\right) \phi_{2}\right)}{\alpha_{2}\left(2-\alpha_{2}\right)\left(1-\left(1-\alpha_{2}\right) \phi_{2}\right)} \\
& \left.-\frac{2 \alpha_{2}^{2} L_{2}\left(1+\alpha_{2} L_{2}\right)\left(\phi_{2}-\theta_{2}\right)\left(1-\phi_{2} \theta_{2}\right)}{\left(1-\phi_{2}\left(1-\alpha_{2}\right)\right)\left(1+\theta_{2}^{2}-2 \phi_{2} \theta_{2}\right)}\right) \\
& \times \operatorname{Var}\left(D_{2, t}\right) \\
& +\left(2\left(1+\alpha_{1} L_{1}\right)\left(1+\alpha_{2} L_{2}\right)\right. \\
& +\frac{2 \alpha_{2}^{2} \phi_{1} L_{2}\left(1+\alpha_{1} L_{1}\right)}{1-\phi_{1}\left(1-\alpha_{2}\right)} \\
& -\frac{2 \alpha_{1}^{2} L_{1}\left(1+\alpha_{2} L_{2}\right) \phi_{2}}{1-\phi_{2}\left(1-\alpha_{1}\right)} \\
& \left.+\frac{2 \alpha_{1} \alpha_{2} L_{1} L_{2} \phi_{2}\left(1-\alpha_{2}\right)}{\left(1-\left(1-\alpha_{1}\right)\left(1-\alpha_{2}\right)\right)\left(1-\phi_{2}\left(1-\alpha_{2}\right)\right)}\right) \\
& \times \psi \sqrt{\operatorname{Var}\left(D_{1, t}\right) \operatorname{Var}\left(D_{2, t}\right)} .
\end{aligned}
$$

This completes the Proof for Proposition 3.

\section{Acknowledgments}

This work was supported by the National Nature Science Foundation of China (no. 61273231) and the Doctoral Scientific Fund Project of the Ministry of Education of China (no. 20090032110031).

\section{References}

[1] J. W. Forrester, "Industrial dynamics - a major breakthrough for decision making," Harvard Business Review, vol. 36, no. 4, pp. 37-66, 1958.

[2] J. W. Forrester, Industrial Dynamics, MIT Press, Cambridge, Mass, USA, 1961.

[3] J. Sterman, "Optimal policy for a multi-product, dynamic, nonstationary inventory problem," Management Science, vol. 12, pp. 206-222, 1989.

[4] H. L. Lee, V. Padmanabhan, and S. Whang, "Information distortion in a supply chain: the bullwhip effect," Management Science, vol. 43, no. 4, pp. 546-558, 1997.

[5] H. L. Lee, P. Padmanabhan, and S. Whang, "Bullwhip effect in a supply chain," Sloan Management Review, vol. 38, pp. 93-102, 1997.

[6] F. Chen, Z. Drezner, J. K. Ryan, and D. Simchi-Levi, "Quantifying the bullwhip effect in a simple supply chain: the impact of forecasting, lead times, and information," Management Science, vol. 46, no. 3, pp. 436-443, 2000.

[7] F. Chen, J. K. Ryan, and D. Simchi-Levi, "The impact of exponential smoothing forecasts on the bullwhip effect," Naval Research Logistics, vol. 47, no. 4, pp. 269-286, 2000.

[8] K. Xu, Y. Dong, and P. T. Evers, "Towards better coordination of the supply chain," Transportation Research E, vol. 37, no. 1, pp. 35-54, 2001.

[9] H. T. Luong, "Measure of bullwhip effect in supply chains with autoregressive demand process," The European Journal of Operational Research, vol. 180, no. 3, pp. 1086-1097, 2007.

[10] T. T. H. Duc, H. T. Luong, and Y.-D. Kim, "A measure of bullwhip effect in supply chains with a mixed autoregressivemoving average demand process," The European Journal of Operational Research, vol. 187, no. 1, pp. 243-256, 2008.

[11] T. T. H. Duc, H. T. Luong, and Y.-D. Kim, "Effect of the thirdparty warehouse on bullwhip effect and inventory cost in supply chains," International Journal of Production Economics, vol. 124, no. 2, pp. 395-407, 2010.

[12] X. Zhang, "The impact of forecasting methods on the bullwhip effect," International Journal of Production Economics, vol. 88, no. 1, pp. 15-27, 2004.

[13] Y. Feng and J. H. Ma, "Demand and forecasting in supply chains based on $\operatorname{ARMA}(1,1)$ demand process," Industrial Engineering Journal, vol. 11, no. 5, pp. 50-55, 2008.

[14] M. Ferrara, R. Mavilia, and F. Lamperti, "The effects of innovation poles and science parks on regional economies in Italy," in Proceedings of the 3rd International Conference on Communication and Management in Technological Innovation and Academy, Recent Advances in Communications, Circuits and Technological Innovation, pp. 196-202, WSEAS Press, Paris, France, 2012.

[15] R. S. Pindyck and D. L. Rubinfeld, Econometric Models and Economic Forecasts, McGraw-Hill, Irwin, Ba, USA, 4th edition, 1998. 


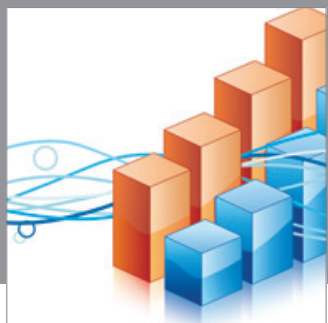

Advances in

Operations Research

mansans

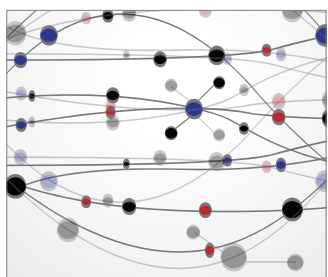

The Scientific World Journal
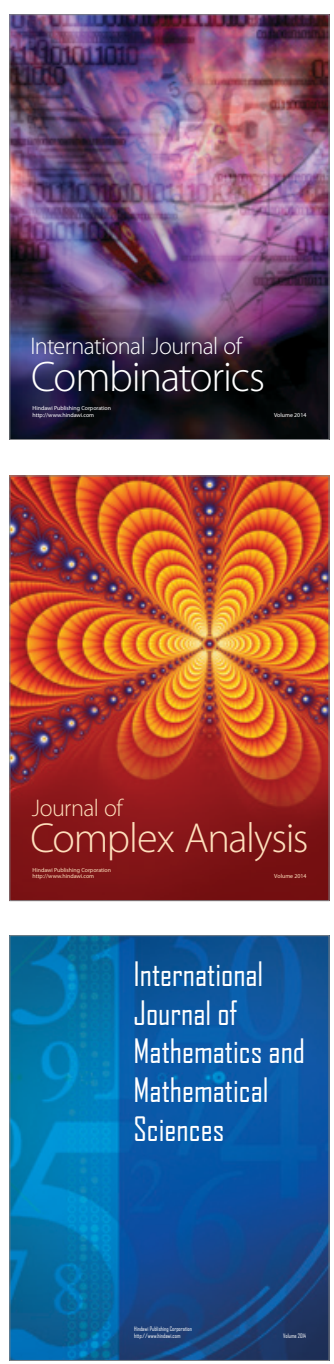
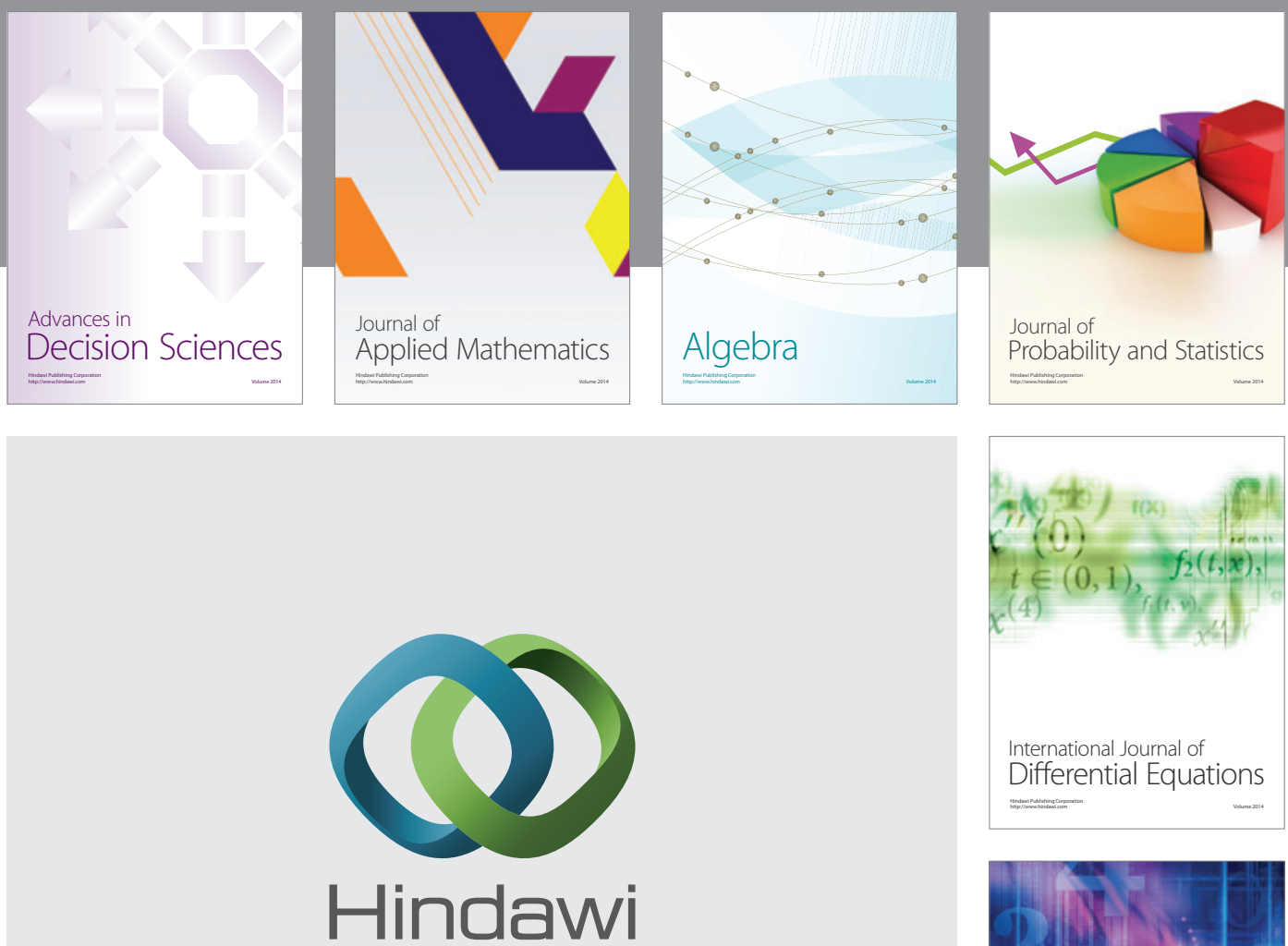

Submit your manuscripts at http://www.hindawi.com
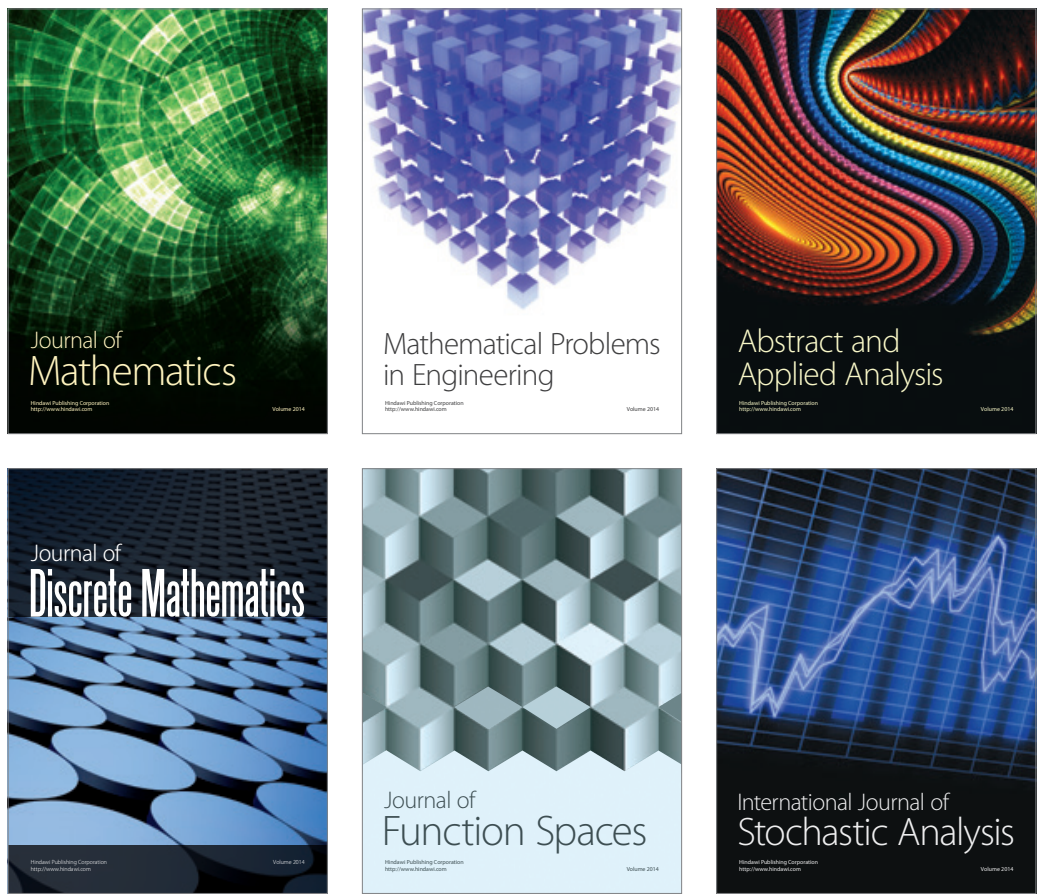

Journal of

Function Spaces

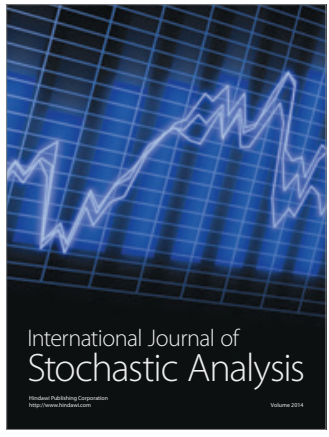

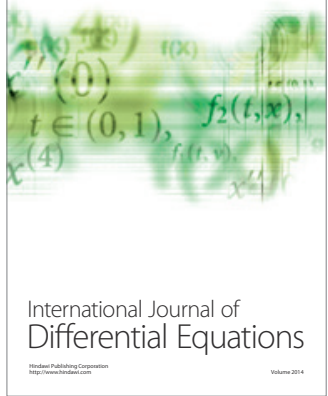
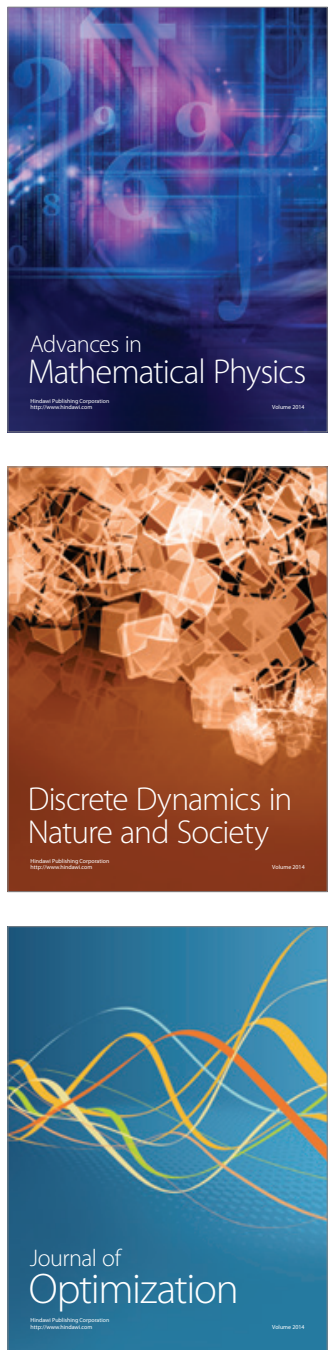